\title{
A CONTENT ANALYSis INVESTIGATING RELATIONSHIPS BETWEEN COMMUNICATION AND BUSINESS CONTINUITY PLANNING
}

Gabriel L. Adkins

Tyler J. Thornton

Kevin Blake

The University of Oklahoma

\begin{abstract}
This study provides an exploratory content analysis of business continuity planning (BCP) literature. The researchers systematically sampled multiple databases and codified artifacts using a set of variables developed by the research team. Based on the analysis, arguments are presented concerning the nature of $B C P$, the state of the $B C P$ literature, and the nature of the conversations taking place in regard to $B C P$ among academics, government/legal institutions, the media, and trade industries. Finally, the researchers demonstrate gaps in the current knowledge on $B C P$ and suggest future directions for applied and theoretical research.
\end{abstract}

Keywords: business continuity; content analysis; risk management; disaster preparedness; knowledge management

In recent years, there has been no shortage of crises and disasters in the United States and abroad, including the Virginia Tech Massacre, Hurricanes Katrina and Rita, the Southeast Asian Tsunami, SARS, Mad Cow Disease, the Enron scandal, the Y2K bug, terrorism in London, Madrid, and the Middle East, and of course the unforgettable 9/11 attacks. In 2008, we are facing one of the worst economic crises since the S\&P index started 80 years ago (Norris, 2008). It is imperative to recognize that everything in the economy is interconnected: corporations, small businesses, the housing market, the stock market, the unemployment rate, the federal government, and people's personal finances. That's why, after the housing bubble burst, it initially affected mortgage lenders and the people who couldn't afford to make payments on their homes anymore but spread to the commercial and service areas and now to the job market. The more people who can't sell their homes, the worse the housing market gets, as everyone is in a race to the bottom to make any 
money they can before they are foreclosed upon. In addition, energy prices are escalating, which means that consumers are attempting to save more and spend less on things they enjoy such as dining out, taking vacations, and other leisure activities. Subsequently, major corporations such as financial institutions and insurance companies recently went insolvent destroying millions of people's lives, who were expecting to receive steady retirement benefits or home loans from the now failed companies.

The list could go on, but a common trend is that these events are inevitable, widespread, and affect all types of organizations and individuals with vastly different missions, cultures, and goals. Knowing that bad things will happen would not be a problem except for this disturbing truth: The vast majority of organizations recognize that crises are inevitable, but far too many are not prepared to deal with them (Jackson, 2006; Pitt \& Goyal, 2004). Swartz (2003) reported that as few as $20 \%$ of organizations have a plan they feel will be effective in the event of an emergency. Among European nations, Ireland is leading the way with continuity planning, with about $52 \%$ of businesses employing technology to back up data and review other emergency management (EM) measures, while Germany, Italy, and France all come in under $35 \%$ (Jackson, 2006). The lack of planning is even more disconcerting when you consider that the private sector in the United States controls as much as $85 \%$ of the country's infrastructure (MCC, 2005) but are least prepared to handle a crisis.

When disasters, crises, or even minor hazards occur in a small or large workplace, it creates serious problems for employers, including massive losses in profits, time, and other resources (Jackson, 2006; Maher \& Zimmerman, 2005). Because it is clear that something bad will eventually happen, it is difficult to comprehend why so many organizations (who risk

\footnotetext{
The members of the research team would like to gratefully acknowledge the assistance of Dr. H. Dan O'Hair, Dr. Jill Edy, and Dr. Glen Hansen in preparing this article for publication. Gabriel Adkins is a doctoral student who is currently working on his dissertation at the University of Oklahoma. His research interests include organizational communication, interorganizational networking, intercultural communication, crisis communication, and communication technology. Tyler J. Thornton is a doctoral student who is currently finishing course work and preparing his dissertation proposal at the University of Oklahoma. His research interests include intercultural communication with an emphasis in hermeneutics, phenomenology, and semiotics. He also does research in organizational communication, networking, and communication technology. Kevin Blake is a staff employee at the University of Oklahoma and a graduate student who is currently finishing course work and preparing his proposal at the University of Oklahoma. His research interests include interorganizational networking and communication technology. Correspondence concerning this article should be addressed to Gabriel L. Adkins, The University of Oklahoma, 1203 Rebecca Lane \#110, Norman, OK 73072; e-mail: gadkins@ou.edu.
} 
losing billions of dollars, stakeholders, resources, and possibly lives) refuse to put in money and time to be prepared for when the problems come. Considering that the business world is generally profit driven, the failure to minimize the risks related to crisis seems particularly troubling. If a business is able to grow and can continue its usual transactions and cycles without being interrupted, or only minimally interrupted, other organizational goals, including increasing profits, will be met. Therefore, insulating an organization against the disrupting forces of a disaster or crisis would seem to be an issue that should be a top priority for organizational leaders.

The study reviews the concept of business continuity (BC), which is directly related to risk management and EM planning. After a brief initial search through some of the literature related to business continuity planning (BCP), we found that this area has received lip service but not much else. Far too many articles are vague for practical use and have little or no theoretical underpinning. We are particularly concerned with the limited amount of communication scholarship we found in this area, considering that it should play a central role in all aspects of risk and EM. In order to better understand and hopefully begin to fill this gap, we proposed and conducted the following content analysis of the BCP literature. The first section defines business continuity and related concepts. We then posit six research questions concerning the BCP literature. These questions address issues such as what events BCP is utilized for, what types of organizations are discussed, what strategies and theories are utilized, and how different communities are discussing BCP. We conducted a content analysis over a large sample of the available literature on business continuity in academic journals, government hearings and testimony, legal news and law reviews, trade journals and magazines, and various media sources from 1997 to 2007 excluding the current economic crisis. The final section shares the results and discusses findings, limitations, and future research possibilities in business continuity.

Because it is clear that something bad will eventually happen, it is difficult to comprehend why so many organizations (who risk losing billions of dollars, stakeholders, resources, and possibly lives) refuse to put in money and time to be prepared for when the problems come. 


\section{LITERATURE REVIEW}

\section{What Is Business Continuity Planning?}

There seems to be a common consensus that there are four or five subsets of risk or EM. Bajgoric (2006) defines the subset of BCP from an information technology (IT) standpoint as, "the ability of a business to continue with its operations even if some sort of failure or disaster occurs" (p. 632). Similar definitions can be found in other areas such as health care management (Iyer \& Bandyopadhyay, 2000), physical facilities management (Pitt \& Goyal, 2004), international business (Hofstede, Van Deusen, Mueller, Charles, \& The Business Goals Network, 2002), international terrorism prevention (Then \& Loosemore, 2006), human resources (Perry \& Mankin, 2005), banking and finance (Hanna, 2005), and a host of government departments, including the Federal Emergency Management Association, the U.S. Energy Department, and the Department of Homeland Security (MCC, 2005). Despite this clearly understood definition, organizations still put this area of planning aside. The two most common reasons cited for the lack of planning are the high costs and extra time (MCC, 2005).

Botha and Gaadingwe (2006) reviewed 20 SEC International Information Security Conferences and found that only 9 of 802 papers (less than $1 \%$ of the entire pool) dealt with $\mathrm{BC}$ issues, and 7 of the 9 that were presented were overly technical and didn't interact with risk management and security issues. Ramleth (2006) concludes that employees in technical fields lack the skills to effectively communicate the importance of $\mathrm{BCP}$ and that these employees need to make the idea simpler so executives can understand it, thereby helping to make it a higher priority in organizational planning. The Department of Homeland Security conducted a survey of 213 top executives and found that security initiatives receive support, but executives rarely are responsible or accountable for security matters even if they have a hand in making security decisions (Edmonson, 2006). The survey also concluded that executives see security as an operations problem rather than as a problem of the whole organization. Furthermore, Hofstede et al. (2002) surveyed over 1,800 students from 21 countries who work as junior managers and professionals during the day and take MBA courses at night (presumably to move up the chain of command). In the near future, this group will likely be responsible for organizational crisis issues. Because they are currently working in an organization, they understand their organization's culture as well as the kinds of goals their businesses want to pursue. The mean rankings of Hofstede's study over the 21 countries showed that managers are primarily most interested in the 
growth of their business and secondarily in BCP. Other management goals addressed in this study included making a profit, gaining power, being ethical, societal responsibilities, being innovative, caring for employees and stakeholders, nationalism, and family interests.

\section{Lack of Collaboration, Unrealistic Optimism, and No National Standards}

Obviously, there is a gap in the communication between departments and among organizations. Originally, BCP was a concept that fell on the shoulders of IT departments and was limited to backing up, protecting, and providing redundancy of data (Gill, 2006), but more recently, risk management is more inclusive of human as well as technical concerns and affects all aspects of an organization. However, organizations still split responsibilities between operations, security, IT, management, and other departments, thereby increasing the risk that something will fall through the cracks. Practitioners suggest that more collaboration should occur to make the most effect on BCP and other EM plans (Edmonson, 2006; MCC, 2005). One of the clearest cases of collaboration in preparation for a known crisis was federal, state, and local governments cooperating with foreign nations, local communities, corporations, schools, and other organizations to address the Y2K computer problem (Carter, 1998; Pearl, 1998; Willemssen, 1998). Both the $9 / 11$ attacks and Katrina made emergency planning much more salient for the government and all other organizations throughout the United States (Kelly \& Peckham, 2002).

Even a brief reading of the 9/11 Commission Report (2004) shows that the United States should have been prepared for a terrorist attack, especially in the globalized society we live in today. Moreover, we knew about Katrina's potential to create damage before she made landfall, and still, many organizations from the federal and local government to businesses and communities failed to be ready when the storm hit. Powell, Bodon, and Hickson III (2001) explain that during the $\mathrm{Y} 2 \mathrm{~K}$ precrisis, there was a sense of apathy among the general population. According to their research, people made two faulty assumptions. First, they felt that the government and businesses had the millennium bug under control because they talked about it for so long and, hence, assumed that they could control other risks. Second, there was no need to prepare because the crisis was not going to affect them personally. Scholars describe such apathy as unrealistic optimism, a widespread concept from personal health problems to organizational crises despite the fact that serious problems, hazards, disasters, and crises occur constantly (Aucote \& Gold, 2005; Covey \& Davies, 2004; Hermand et al., 2003; Park, Scherer, \& Glynn, 
2001). Whether they are predictable or not, the clear message is that organizations should prepare for when, not if, a disaster and/or crisis will occur.

Upon finding no national standard for emergency preparedness in the private sector, the 9/11 Commission recommended that the American National Standards Institute create a comprehensive set of guidelines and standards to help the private sector prepare itself for future terrorist attacks, natural disasters, or other crises (MCC, 2005). This was another attempt to create collaboration between and among organizations throughout the country as a means to increase the nation's security. John Azzarello, former counsel to the Commission, explained that such standards would allow a common terminology or language that all entities could understand (MCC, 2005). Up to this point, technical language barriers across organizations have decreased successful collaborative efforts. Just like the idea that all departments in one company should work together to create a successful plan for their business, the national standard would allow many companies and government bodies to interact and create the best plan for preparing for and responding to disastrous situations. However, the drawback to such a national standard is that there are few incentives for compliance. One suggestion was to have credit rating and ensure that insurance industries provide monetary incentive, but even that is a difficult process since insurance companies don't want to lose money on insuring risky businesses. One would think that saving lives and profits might be enough, but this is simply not the case. Additional problems with previously existing guidelines such as the National Fire Protection Association (NFPA) 1600 guides include vague definitions, legal and liability issues, and untested criteria (NFPA, 2007). While this and other documents are a start, they are simply not enough. Furthermore, individuals must adapt to their particular circumstances, so standards are not nationally consistent. There are problems with how communication is happening when it comes to $\mathrm{BCP}$, and there needs to be some direction on how to make the process more useful and collaborative.

\section{Scholars describe such apathy as unrealistic optimism, a widespread concept from personal health problems to organizational crises despite the fact that serious problems, hazards, disasters, and crises occur constantly.}




\section{Knowledge Management Theory}

Knowledge management theory provides a framework to make BCP more relevant and practical in EM planning. Initially, Newman and Conrad (1999) defined knowledge management "[as] a discipline that seeks to improve the performance of individuals and organizations by maintaining and leveraging the present and future value of knowledge assets" (p. 2). They further describe a model where agents within organizations create, utilize, transfer, and retain all kinds of explicit, ${ }^{1}$ implicit, ${ }^{2}$ and tacit ${ }^{3}$ knowledge artifacts (bits of information). If applied correctly, Newman and Conrad (1999) suggest, "the framework is a general purpose tool that can be applied to variety of problems and solutions and adapted to individual work styles". For example, if organizations lack effective and strategic communication because they don't know how to conduct BCP, then they can't prepare for future disasters. Using the model, we can illustrate the importance of knowing what knowledge currently exists, who has it, how it is disseminated, and whether it is in fact relevant and practical to a particular organization or situation. Once the known body of knowledge is thereby properly managed, we can begin the process of finding gaps in the knowledge and needed information that is currently not available. Based on what we have seen thus far, the state of the literature indicates that knowledge regarding $\mathrm{BCP}$ is in dire need of management; this study seeks to assist with the process of understanding the knowledge that currently exists, in hopes that it will lead to the identification of knowledge gaps and the eventual generation of the knowledge needed to fill those gaps in regard to $\mathrm{BCP}$.

\section{Research Questions}

We offer the following research questions (RQs) because our search indicated an obvious lack of knowledge regarding BCP, particularly in relation to communication in the planning process within and among organizations:

RQ1: According to the literature, what types of events should organizations utilize BCP for?

$R Q 2:$ What types of organizations are represented in the BCP literature?

$R Q 3$ : What types of communication technologies are discussed as part of $\mathrm{BCP}$ in the literature?

RQ4: What strategic elements of $\mathrm{BCP}$ are discussed in the literature?

RQ5: What communication theories are utilized or discussed in the $\mathrm{BCP}$ literature? 
RQ6: Are academics, trade organizations, the media, and government/legal organizations discussing the same issues in regard to $\mathrm{BCP}$ ? If not, what are the differences between these groups?

\section{METHOD}

We conducted a content analysis of the literature by searching five databases, including ABI/INFORM, Web of Science, LexisNexis Academic Universe, EBSCOhost, and ERIC. We used one search term-business continuity - and limited the dates to the last 10 years (1997-2007) and full text articles only. Our combined search located more than 2,500 articles, which we included in the sample frame for analysis. Furthermore, we stratified the articles into four subbodies of literature: academic articles, trade publications, media articles, and government/legal publications.

In order to find the answers to our research questions, which we could then place in the knowledge management framework to make the most effective use of the information for organizations, we used a grounded theory approach. We used the first 50 listings of each database to establish the initial code sheet categories. We created additional categories as necessary after the initial coding process and interreliability testing. We created these only if all three coders agreed that they were necessary. Because this is only a sample of the total body of available literature on BCP, we didn't want to limit potential data that could help answer the research questions.

\section{Code Sheets}

Our initial code sheet (see the appendix) listed eight categories for each event type, from natural phenomena such as weather-related events and diseases to human-made problems like terrorism and corporate scandals. We included 16 types of organizations, some of which were domestic and international governments; banking and finance; food, retail, and hospitalities services; IT services; and various industries from manufacturing to health care/hospitals. We represented nine types of communication technologies from a cell phone to the media of written and face-to-face communication. We had 10 BCP strategy elements, including various kinds of training, networking within and among organizations, and what, if any, written plans the organizations had. Finally, we included two communication theories: systems theory and networking theory. After we concluded the intercoder reliability test, we expanded the code sheet (see the appendix) to include a total of 12 
event types, 27 organization types, 17 communication technologies, 25 strategy elements, and 3 categories for communication theories (networking, systems, and other).

\section{Sampling Frame, Sample Selection, and Description of Sample}

In order to learn the coding process, we conducted a small intercoder reliability test. This test was a nonsystematic random sample and included one academic, five trade, five government/legal, and five media articles, which all three researchers coded. Of the 16 articles assigned for this sample, 13 were located and coded by all three coders; the remaining 3 articles were coded by two of the coders and were eliminated from the analysis. The resulting intercoder reliability rate was $94 \%$, based on the calculation of simple percentage agreement that was initially utilized to determine general reliability on this initial sample. After learning how to code, we conducted a second intercoder reliability test as a part of the actual sample. We searched the databases to compile the four stratified bibliographies and then eliminated any duplicates between the four sets. The articles from the initial intercoder reliability test were not included in the final sample frame. This left 225 media, 152 academic, 1,134 trade, and 484 government/legal articles $(N=1,995)$.

We then selected 75 articles from each of the four types of publications for the final sample (so that we would have equal representation of all four publication types in our sample), using a random number generator to pick each article, which gave us an $N$ of 300 in the final sample of articles to code. Several of the articles chosen in the final sample ( 6 academic, 1 media, and 1 government publications) were not locatable by the authors during the coding process, resulting in a final sample size of 292 articles coded. For the final intercoder reliability analysis, 28 articles were selected randomly from the 300 articles originally selected for inclusion in the sample; all 28 articles for the reliability analysis were located and coded. Table 1 presents a breakdown of the sample by type of publication.

Over $55 \%$ of the articles in the final sample were published between 2004 and 2006, as shown in Table 2. When a histogram of the dates of publication (see Figure 1) is created for our sample, a significant increase in BCP publications occurs during the years 2002 to 2006; the number of publications in our sample during this period went from a previous average of 6.2 per year from 1997 to 2001 to an average of 46.6 per year between 2002 and 2006. 
Table 1. Publication Type Distribution of Coded Articles

\begin{tabular}{lcc}
\hline Publication Type & Number of Articles & Percentage of Total Sample \\
\hline Academic publication & 69 & 23.6 \\
Trade publication & 75 & 25.7 \\
Media article & 74 & 25.3 \\
Government/Legal publication & 74 & 25.3 \\
\hline
\end{tabular}

Table 2. Publication Date Distribution of Sample

\begin{tabular}{lcc}
\hline Publication Year & Number of Articles & Percentage of Sample \\
\hline 1997 & 4 & 1.4 \\
1998 & 12 & 4.1 \\
1999 & 16 & 5.5 \\
2000 & 7 & 2.4 \\
2001 & 8 & 2.7 \\
2002 & 30 & 10.3 \\
2003 & 42 & 14.4 \\
2004 & 50 & 17.1 \\
2005 & 51 & 17.5 \\
2006 & 60 & 20.5 \\
2007 & 12 & 4.1 \\
\hline
\end{tabular}

We assert that the initial spike in publication of $\mathrm{BCP}$ literature is due in no small part to the 9/11 terrorist attacks and is sustained mostly as a result of the hurricane Katrina disaster that occurred in 2005. During both of these events, it is likely that organizations and publishers were more salient of the potentials both for a disaster to occur and of the devastating impacts that a disaster could have on an unprepared organization. Unfortunately, the graph also shows that our sample indicates a significant decline in BCP publications during 2007; this is possibly due to one of two factors (or a combination of both): This drop-off is either because the sample was collected during the second quarter of 2007, or it is quite possible that interest in BCP and the salience of potential disaster degenerates once a major public crisis or disaster gives way to a period of relative stability. There is some anecdotal evidence supporting the assertion that the latter possibility is likely to be a significant factor in the drop-off of publications on BCP in 2007; assuming that an even distribution of publications throughout the year would have been selected for the sample, only 36 articles from 2007 would have appeared in the sample, as opposed to 60 articles from 2006. 


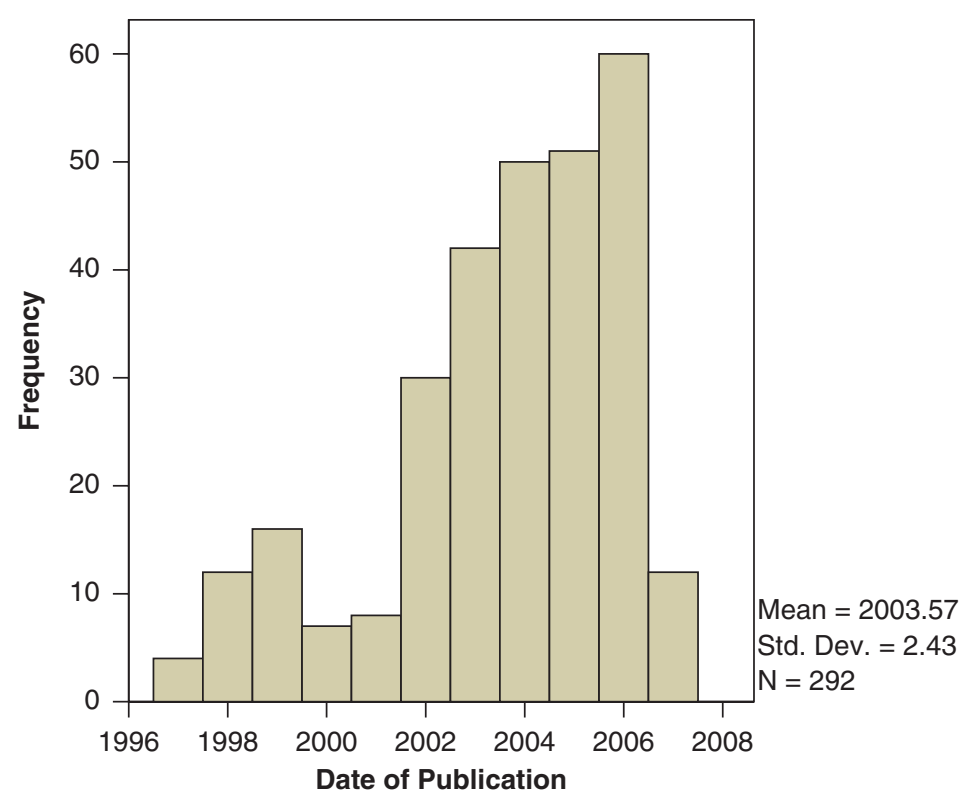

Figure 1. Histogram of Publication Date Distribution

We assert that the initial spike in publication of BCP literature is due in no small part to the 9/11 terrorist attacks and is sustained mostly as a result of the hurricane Katrina disaster that occurred in 2005.

\section{Coding Procedure and Intercoder Reliability}

The unit of measurement was the article. Each researcher read entire articles, not just abstracts or titles. Texts were coded, whereas additional tables and notes were not included. The unit of observation was the category items. The SPSS data file consisted of basic code items containing coder numbers, codes for stratifications, publication dates for every article, and unit numbers for each article. Each category item was individually "dummy coded": If a 
particular category was present, it received a 1 , and if it was not present, it received a 2 . There were 87 total variables in the final SPSS file, 82 of which were binary categories coded as described above.

Intercoder reliability analysis was conducted using the Cohen's kappa statistic. Cohen's kappa (Cohen, 1960) is designed to measure the reliability between two coders; in order to adjust the statistic to accommodate the use of three coders, a modified procedure for obtaining Cohen's kappa was used. Our procedure for calculating Cohen's kappa consisted of five steps: (a) calculating the percentage agreement between each of the coders for each coded item (comparing coders 1 and 2, 2 and 3, and 1 and 3 separately), (b) averaging the percentage agreement across the three coders for each coded item in order to arrive at an overall percentage of agreement for each item, (c) calculating the average percentage agreement between the three coders for each major category (disaster/crisis types, organization types, communication technologies, BCP strategy elements, and communication theory usage), (d) using the average percentage agreement for each major category in the kappa calculation, and (e) calculating an average overall kappa for both the initial and the final intercoder reliability samples by averaging the obtained kappa values for each major category in order to compare overall reliability between the initial and final samples. The Cohen's kappa calculation utilized was the following: $\kappa=(P(\mathrm{a})-P(\mathrm{c})) /(1-P(\mathrm{c}))$, where $P(\mathrm{a})=$ percentage agreement and $\mathrm{P}(\mathrm{c})=$ percentage expected chance agreement. Percentage of expected chance agreement was designated at $50 \%$ in these calculations.

Thirteen units were coded for the initial intercoder reliability check (see Table 3). The overall kappa value obtained for the initial intercoder reliability was .7459. The kappa for the disaster/crisis types showed a fairly high level of intercoder reliability $(\kappa=.8077$, range $=.7436$ to 1.00$)$, as did the kappa values obtained for organization type ( $\kappa=.8063, r=.6410$ to 1.00$)$. A moderate level of intercoder reliability was indicated by the kappa statistic obtained for BCP planning elements $(\kappa=.7374, r=.6410$ to 1.00$)$. Reliability for communication theory usage $(\kappa=.6924, r=.8462)$ and communication strategies $(\kappa=.6859, r=.6923$ to .9487$)$ fell slightly below the desired level of reliability $(\kappa=.70)$. Table 3 provides a detailed summary of the Cohen's kappa calculations for the initial intercoder reliability analysis.

For the final intercoder reliability measure (see Table 4), 28 units from the final sample were coded by all three coders. The 28 articles selected for this procedure were selected randomly using a random number generator. The overall kappa obtained for the final intercoder sample was .7459 , reflecting no overall change in the moderate level of intercoder 


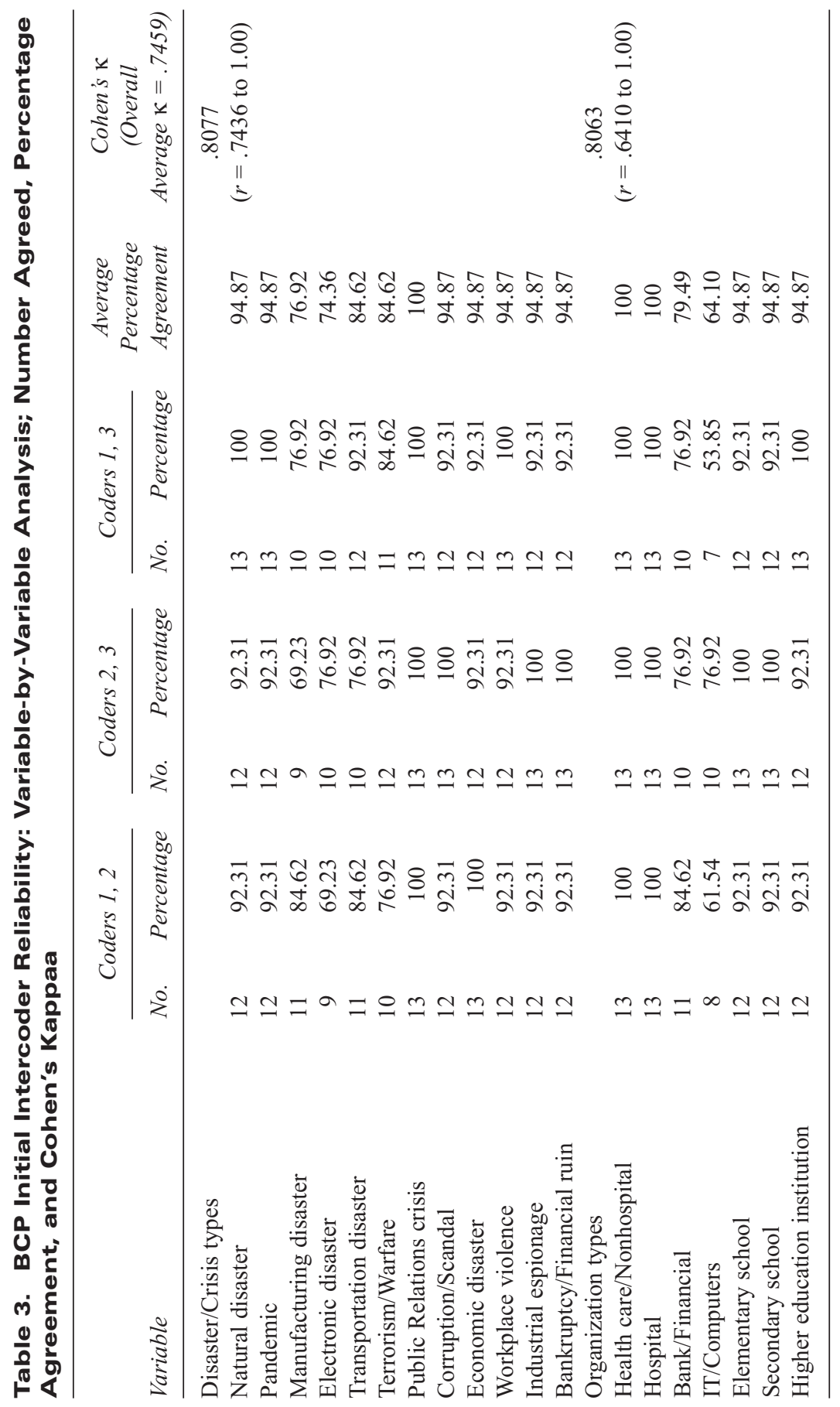




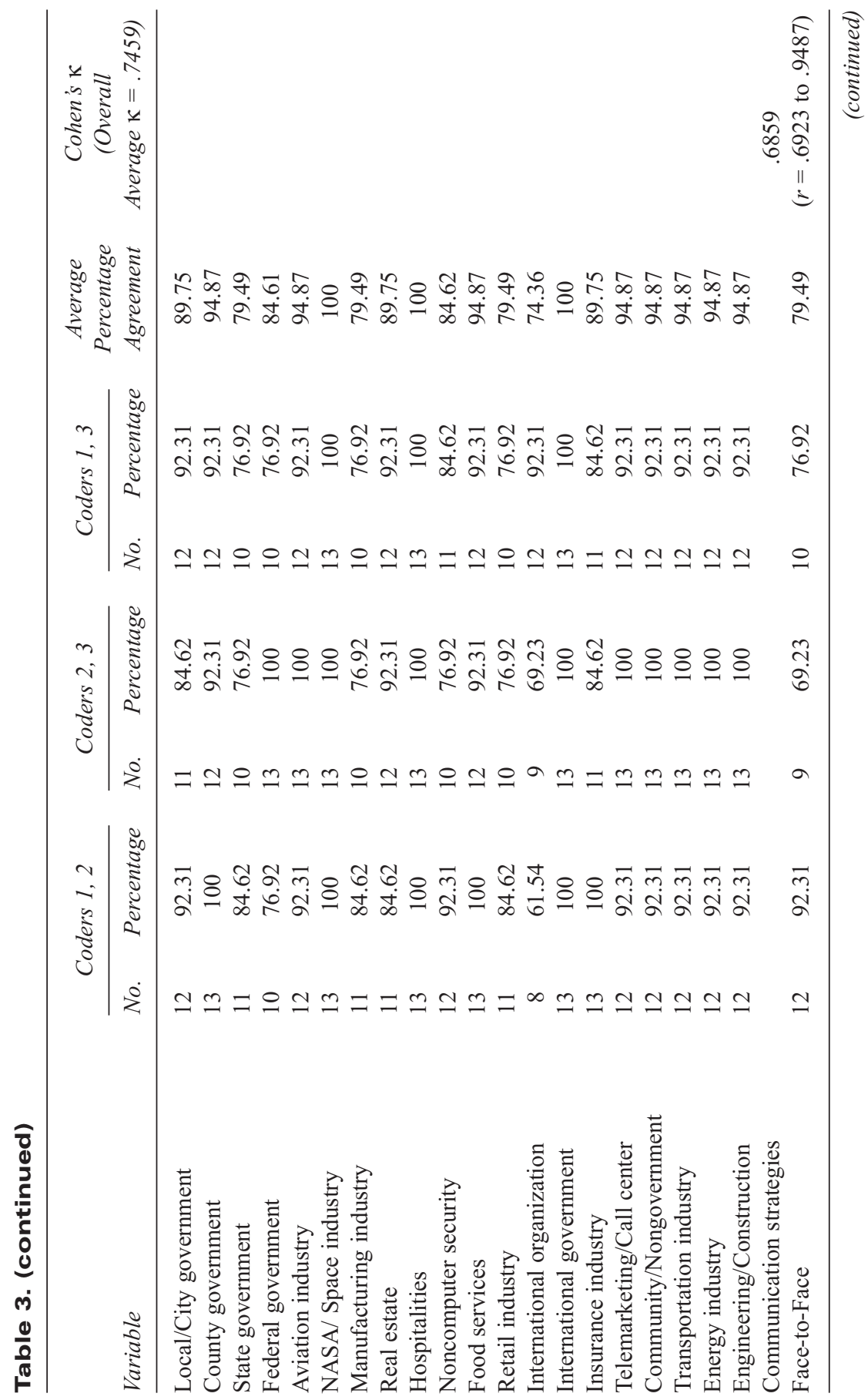




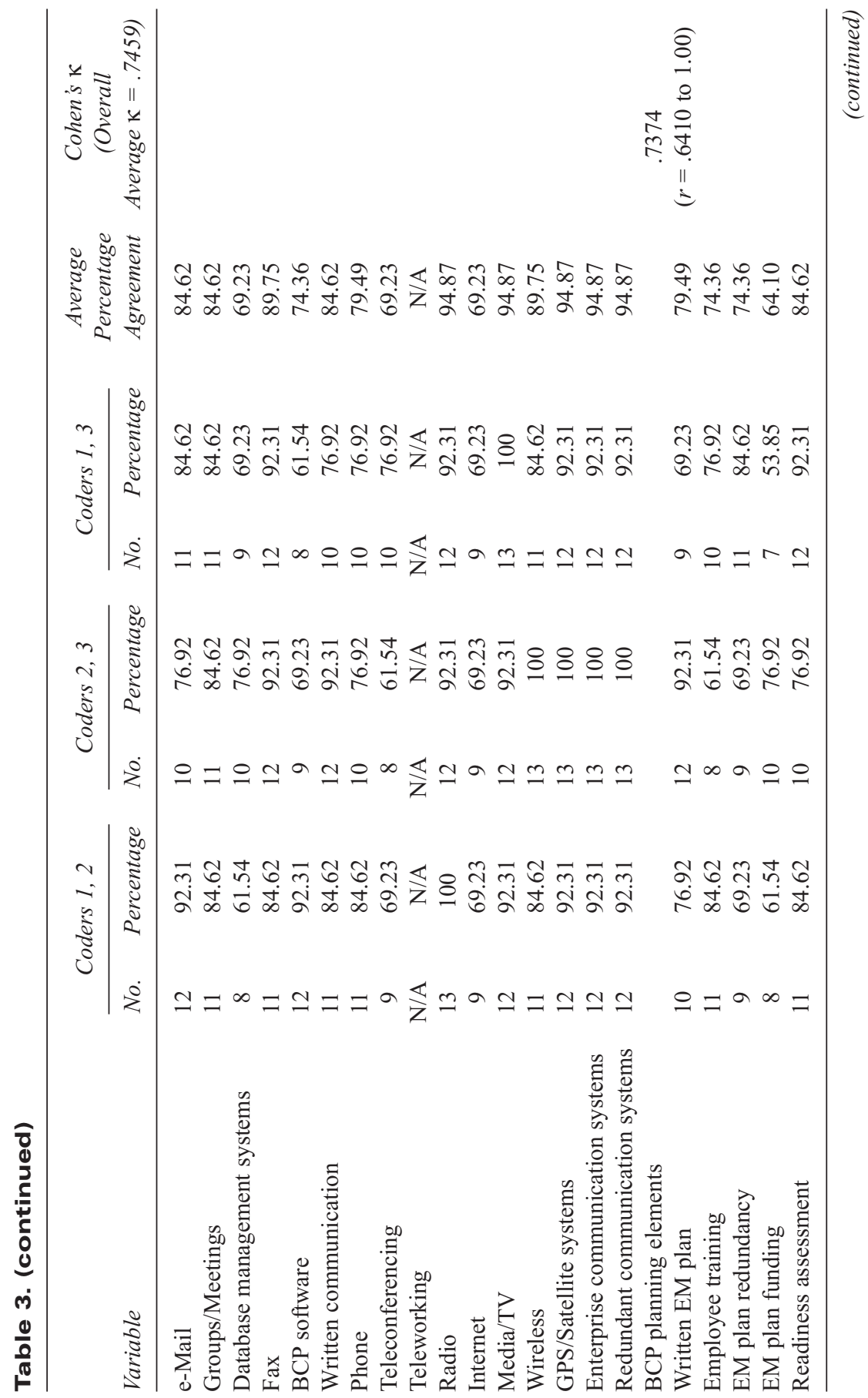




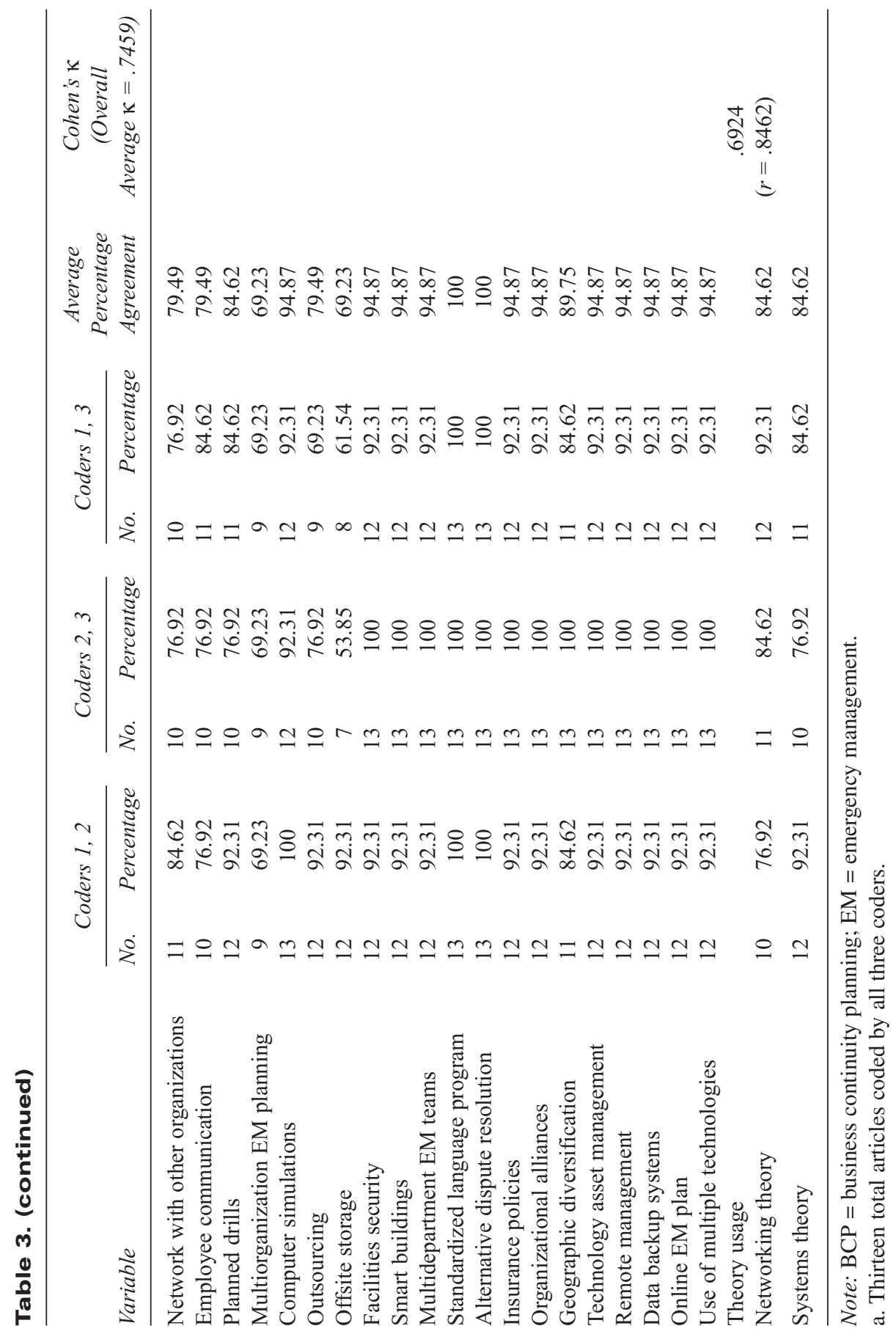




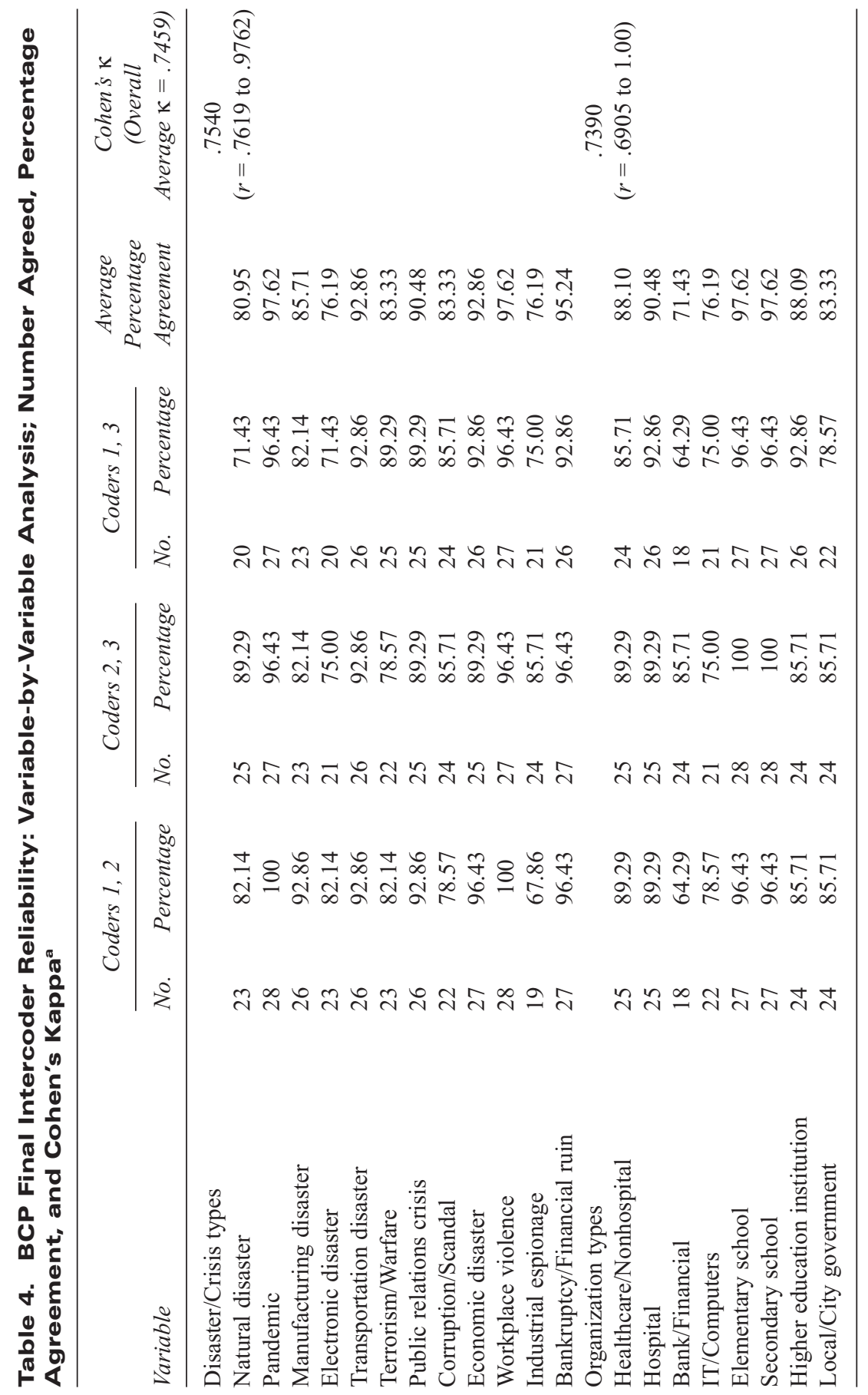




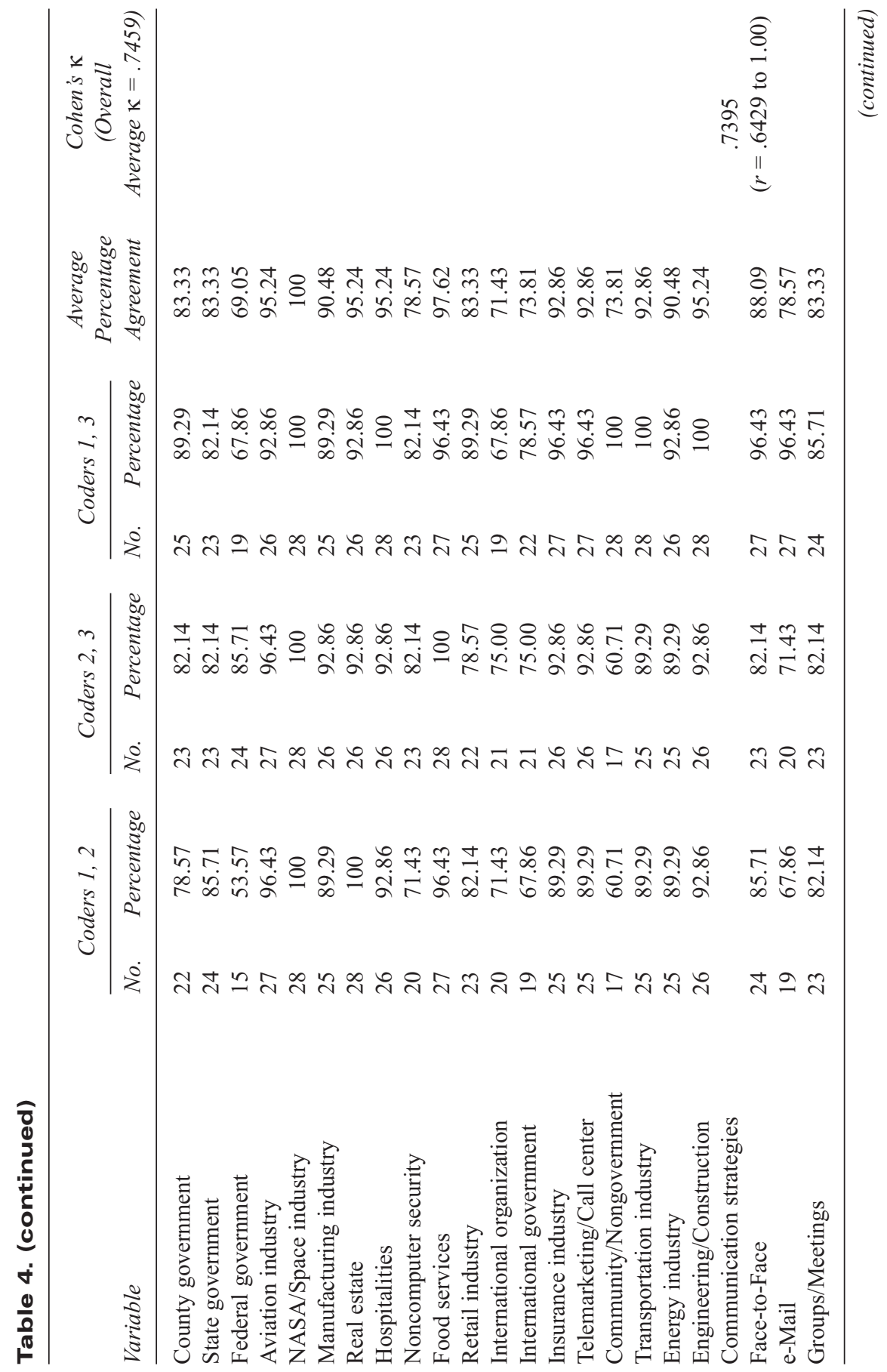




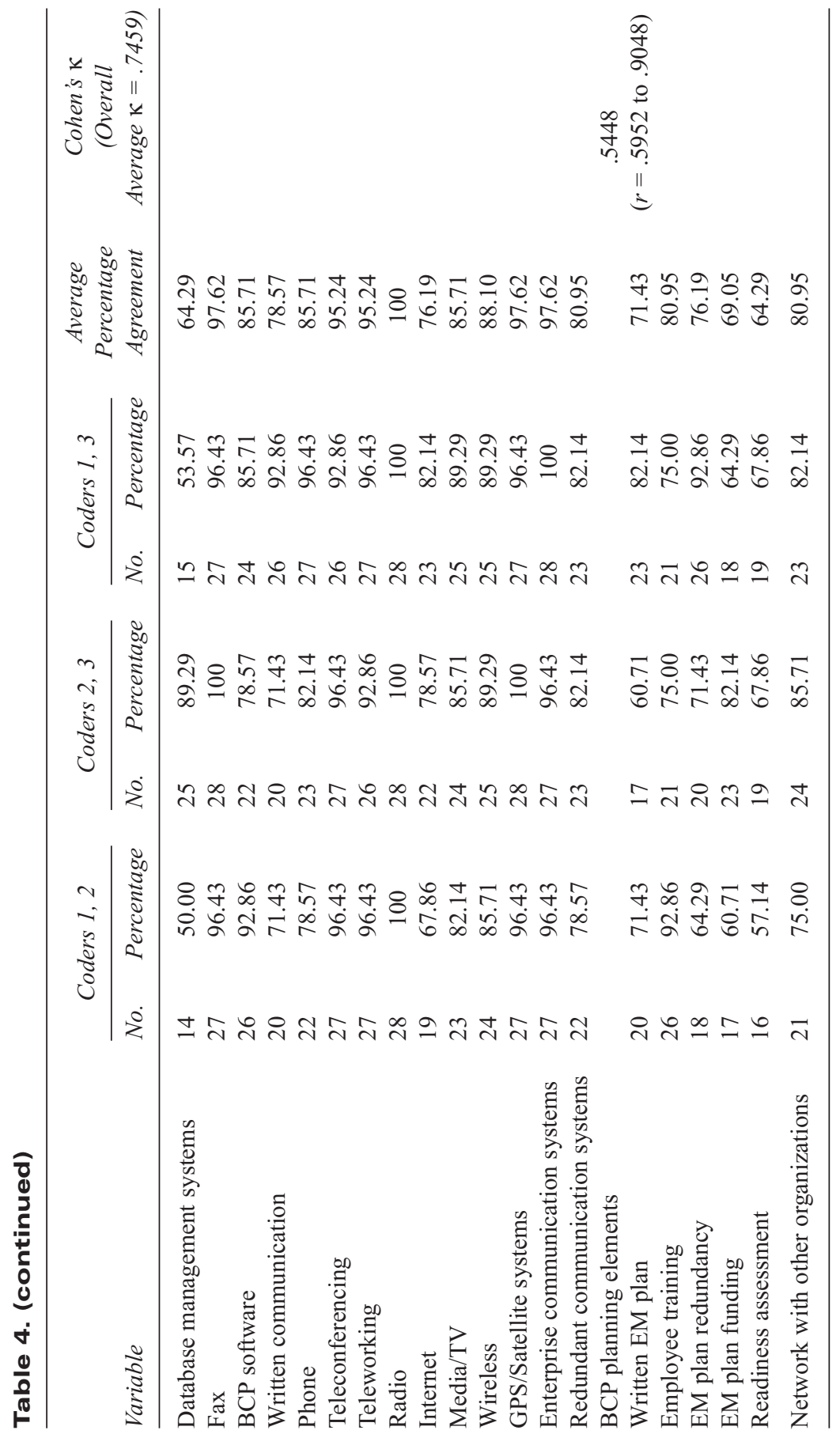




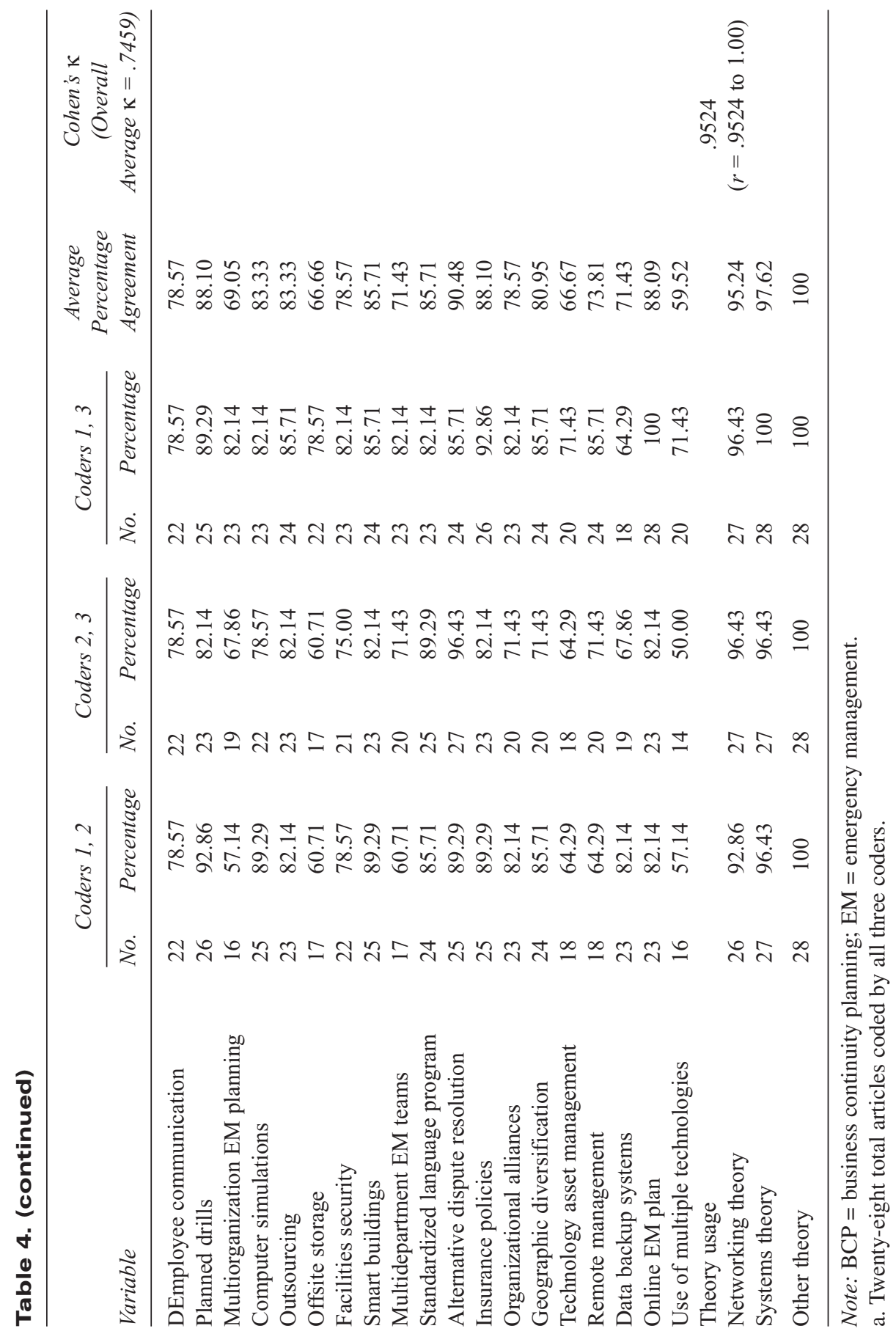


reliability between the initial and final reliability checks. Communication theory usage demonstrated the highest level of reliability in the final sample $(\kappa=.9524, r=.9524$ to 1.00$)$, with disaster/crisis type $(\kappa=.7540$, $r=.7619$ to .9762$)$, communication strategies $(\kappa=.7395, r=.6429$ to $1.00)$, and organization types $(\kappa=.7390, r=.7390$ to 1.00$)$ demonstrating a moderate level of intercoder reliability. The only major category to fall below our desired threshold of .70 in the final reliability sample was BCP planning elements ( $\kappa=.5448, r=.5952$ to .9048$)$. Table 4 provides a complete summarization of the final intercoder reliability analysis.

\section{RESULTS}

Our final sample size was $N=292$. This number includes the 28 articles we chose for intercoder reliability testing; the coding of the sample therefore resulted in the generation of 348 total code sheets. Articles that were coded by all three coders for the final reliability analysis were combined (by unit number) into a single line of code in which the designated presence of a variable by any one of the coders was coded as being present, thereby giving the benefit of the doubt that the variable was actually present in that particular unit.

Although one of our major categories fell below our desired reliability threshold, we felt that the overall numbers obtained and the reliability numbers of the other major categories indicated that, as a whole, the coders were coding in a reliable fashion. Additionally, our choice to use the more stringent $50 \%$ chance agreement expectation from the original kappa statistic calculation formula (which is the designated threshold for comparing reliability between two coders) in the calculations of the reliability statistic created additional weighting against the reliability levels in this study; the three-coder format utilized for this study should arguably have been calculated using a $33.33 \%$ of expected chance agreement. We believe that the level of intercoder reliability obtained between the three coders indicates that the coders were coding in a similar fashion and that the results generated in this study are generally reliable.

Our first research question concerns what types of events BCP should be utilized for according to the literature examined. As can be seen in Table 5, the data show that $31.8 \%$ of the cases refer to natural disasters $(n=93), 11.3 \%$ are pandemic/employee health $(n=33), 7.2 \%$ are manufacturing disasters $(n=21), 41.8 \%$ are electronic disasters $(n=122), 3.8 \%$ are transportation disasters $(n=11), 34.6 \%$ are terrorism/warfare $(n=101), 7.2 \%$ are public relations crises $(n=21), 6.8 \%$ are corruption/scandal $(n=20), 7.2 \%$ are 
Table 5. Types of Event BCP Is Utilized For

\begin{tabular}{lcc}
\hline Event Type & Frequency & Percentage of Units Represented In \\
\hline Natural disaster & 93 & 31.8 \\
Pandemic/Employee health & 33 & 11.3 \\
Manufacturing disaster event & 21 & 7.2 \\
Electronic disaster & 122 & 41.8 \\
Transportation disaster & 11 & 3.8 \\
Terrorism/Warfare & 101 & 34.6 \\
Public Relations crisis & 21 & 7.2 \\
Corruption/Scandal & 20 & 6.8 \\
Economic Disaster/ & 21 & 7.2 \\
$\quad$ Market collapse & & \\
Workplace violence & 12 & 4.1 \\
Industrial espionage & 41 & 14.0 \\
Financial ruin/bankruptcy & 28 & 9.6 \\
\hline
\end{tabular}

Note: $\mathrm{BCP}=$ business continuity planning.

economic disasters $(n=21), 4.1 \%$ are workplace violence $(n=12), 14.0 \%$ are industrial espionage $(n=41)$, and $9.6 \%$ are financial ruin/bankruptcy $(n=28)$. Clearly, three types of events dominate the BCP literature: natural disasters, electronic disasters, and terrorism/warfare events. It is startling how little attention the other types of events are receiving.

In our second research question, we asked what types of organizations are represented in the BCP literature. As we can see in Table 6, three types of organizations dominate the literature: banking/financial, IT/computer systems, and federal government. The banking and IT organizations are each represented in over $35 \%$ of the literature coded, while the federal government is represented in over $25 \%$ of the sample.

Our third research question inquires as to what types of communication technologies are discussed in the BCP literature. We found that Internet and Web site communication is a dominant technology (represented in over $22 \%$ of the sample), followed closely by database management systems. The use of phones and cellular phones seems to dominate the type of communication channel relied on in BCP (represented in $13.4 \%$ of the sample). Table 7 provides a summary of the results of our findings concerning the use of communication technology in BCP.

The fourth research question we asked in this study concerns what strategic elements of BCP are discussed in the literature. Table 8 provides a listing of these elements and our findings concerning this research question. What we cannot know from this study (partially as a result of the 
Table 6. Types of Organizations BCP Is Utilized For

\begin{tabular}{lrc}
\hline Organization Type & Frequency & Percentage of Units Represented In \\
\hline Health care/Nonhospital & 21 & 7.2 \\
Hospital & 15 & 5.1 \\
Bank/Financial & 107 & 36.6 \\
IT/Computer systems & 172 & 58.9 \\
Elementary school & 6 & 2.1 \\
Secondary school & 4 & 1.4 \\
Higher education institution & 14 & 4.8 \\
Local city government & 24 & 8.2 \\
County government & 25 & 8.6 \\
State government & 30 & 10.3 \\
Federal/National government & 79 & 27.1 \\
Aviation industry & 15 & 5.1 \\
NASA/Space industry & 4 & 1.4 \\
Manufacturing industry & 28 & 9.6 \\
Real estate & 8 & 2.7 \\
Hospitalities services & 11 & 3.8 \\
Noncomputer security systems & 33 & 11.3 \\
Food services & 10 & 3.4 \\
Retail & 22 & 7.5 \\
International organization & 44 & 15.1 \\
International government & 28 & 9.6 \\
Insurance & 38 & 13.0 \\
Telemarketing & 14 & 4.8 \\
Community/Nongovernment & 32 & 41.0 \\
Transportation & 14 & 4.1 \\
Energy & 12 & 2.7 \\
Engineering/Construction & 8 & \\
\hline & & \\
\hline
\end{tabular}

Note: $\mathrm{BCP}=$ business continuity planning.

limitation of the coding procedure used) is to what extent these elements are ideal strategies versus practically applied tools. Based on the literature we have read so far, most of these strategic elements seem to be directed in the context of what should be done but are not utilized to their full potential in actual BCP practice. The exception to this seems to be an agreement on the importance of written EM plans (represented in over $40 \%$ of the sample literature), technology asset management strategies (represented in over 40\%), and threat assessment/readiness programs (36.6\% of the sampled units mentioned this) as practical tools; but the widespread usage of even these strategic elements is questionable. 
Table 7. Types of Communication Strategies Utilized in BCP

\begin{tabular}{lcc}
\hline Communication Strategy & Frequency & Percentage of Units Represented In \\
\hline Face-to-face communication & 14 & 4.8 \\
e-Mail & 30 & 10.3 \\
Meetings/Group communication & 28 & 9.6 \\
Database Management systems & 59 & 20.2 \\
Fax & 2 & .7 \\
BCP software programs & 48 & 16.4 \\
Written communication & 20 & 6.8 \\
Phone/Cell phone & 39 & 13.4 \\
Teleconferencing & 10 & 3.4 \\
Teleworking/Telecommuting & 27 & 9.2 \\
Radio & 5 & 1.7 \\
Internet/Web site & 66 & 22.6 \\
Media/Television & 15 & 5.1 \\
Wireless & 29 & 9.9 \\
GPS/Satellite & 4 & 1.4 \\
Enterprise communication systems & 6 & 2.1 \\
Redundant communication systems & 23 & 7.9 \\
\hline
\end{tabular}

Note: $\mathrm{BCP}=$ business continuity planning.

The fifth research question asks what communication theories are discussed in the $\mathrm{BCP}$ literature. The findings for this question are both depressing and potentially exciting for communication scholars. On the downside, we have found that any mention of communication theory only occurs in $6.16 \%$ of the literature coded. Table 9 provides a summary of the representation of communication theory found in the sample of BCP literature coded in this research project. Based on this, it would seem that the work of communication scholars is largely lacking in practical application to BCP strategies. Investigation in this area could prove to be a fruitful ground both for theoretical development and as new territory for practical applications of communication scholarship. The lack of communication theory in the literature indicates a potential lack of understanding as to how communication can influence BCP effectiveness and/or the ways in which communication scholarship can contribute to enhanced models for BCP practitioners to utilize. This is a potential area of opportunity for theoretical applications that communication scholars need to more fully explore.

The sixth and final research question inquires as to the similarities and differences in the literature discussion of BCP between academics, trade organizations, the media, and government/legal organizations. In order to 
Table 8. Elements of BCP Planning

\begin{tabular}{lcc}
\hline Element of BCP Plan & Frequency & Percentage of Total \\
\hline Written EM plan & 125 & 42.8 \\
Regular training & 66 & 22.6 \\
EM plan redundancy & 39 & 13.4 \\
EM plan funding & 60 & 20.5 \\
Ongoing threat/Readiness assessment & 107 & 36.6 \\
Communication with networked organizations & 83 & 28.4 \\
Communication with employees & 79 & 27.1 \\
Planned drills & 48 & 16.4 \\
Multiorganizational EM planning & 43 & 14.7 \\
Simulations/Modeling & 51 & 17.5 \\
Outsourcing & 76 & 26.0 \\
Offsite storage & 69 & 23.6 \\
Facilities security & 39 & 13.4 \\
Smart buildings & 19 & 6.5 \\
Multi-department EM teams & 58 & 19.9 \\
Standardized language programs & 16 & 5.5 \\
Alternate dispute resolution & 8 & 2.7 \\
Insurance policies & 54 & 18.5 \\
Organizational alliances & 36 & 12.3 \\
Geographic diversification & 78 & 26.7 \\
Technology asset management & 121 & 41.4 \\
Remote management & 32 & 11.0 \\
Data backups & 92 & 31.5 \\
Online EM plan & 12 & 4.1 \\
Use of multiple technologies & 70 & 24.0 \\
\hline NotercP buis & &
\end{tabular}

Note $: \mathrm{BCP}=$ business continuity planning; $\mathrm{EM}=$ emergency management.

Table 9. Use of Communication Theory in BCP Literature

\begin{tabular}{lcc}
\hline Communication Theory & Frequency & Percentage of Units Represented In \\
\hline Networking theory & 7 & 2.4 \\
Systems theory & 4 & 1.4 \\
Other communication theory & 7 & 2.4 \\
\hline
\end{tabular}

Note: $\mathrm{BCP}=$ business continuity planning.

examine this issue, cross-tabulations were run between the types of literature and each of the variables coded for. The results of these cross-tabulations can be seen in Tables 10 to 14 . The cross-tabulation data were then analyzed for patterns indicating issues of significant interest 
(represented in at least $25 \%$ of a given body of literature), both in the individual bodies of literature and across the bodies of literature. A final analysis of the cross-tabulation data looked for indications of significant similarities and differences ( $\leq 10 \%$ disparity for similarity, $\geq 10 \%$ disparity for difference) in the conversations about BCP issues occurring between the various bodies of literature.

Regarding the relationship between the types of disaster/crises that are mentioned in the BCP literature and the types of publications that are represented, it is interesting to first note that three disaster types dominate the literature across all three categories: natural disasters (academic $[\mathrm{A}]=47.83 \%$, government/legal $[\mathrm{G}]=27.03 \%$, media $[\mathrm{M}]=25.68 \%$, trade $[\mathrm{T}]=28 \%$ ), electronic disasters $(\mathrm{A}=55.07 \%, \mathrm{G}=43.24 \%, \mathrm{M}=39.19 \%, \mathrm{~T}=30.67 \%)$, and terrorism/warfare $(\mathrm{A}=40.58 \%, \mathrm{G}=36.49 \%, \mathrm{M}=31.08 \%, \mathrm{~T}=30.67 \%)$. Table 10 provides a summary of the findings concerning the types of disasters/crises found in each body of literature. We believe that the dominance of these disaster types across all of the bodies of literature in these areas is explained by the salience (Kelly \& Peckham, 2002) created for these disaster types as a result of the Y2K bug, Hurricane Katrina, and the 9/11 terrorist attacks.

Another pattern evident in the analysis of disaster types is that with the exception of trade publications (in which both electronic disasters and terrorism/warfare are equally represented), electronic disasters are mentioned in a higher percentage of each body of literature than are the other two dominant categories. We believe that this is interesting because it could indicate that the groups represented via these bodies of literature are more likely to focus on disasters that can be potentially averted by taking action within the system (i.e., computer systems can be updated to be Y2K compliant, thereby averting the disaster) than those disasters that are perceived to be inflicted on and unavoidable by the affected systems (i.e., natural disasters and terrorist attacks are generated by forces outside of the victimized system).

An analysis of the disparities between the bodies of literature in terms of disaster type demonstrates that academics are having a conversation in their literature that is different from that of the other groups. While all of the literature emphasizes natural disasters and electronic disasters, these issues are represented in a much higher percentage (over 10\% more) of the academic literature than in the literature of the other groups. Additionally, the academic literature $(\mathrm{A}=24.64 \%)$ discusses industrial espionage much more frequently than the other groups $(\mathrm{G}=5.41 \%, \mathrm{M}=12.16 \%, \mathrm{~T}=14.67 \%)$. Finally, we see another disparity between the conversations of academic (14.49\%) and government/legal (16.22\%) publications versus those of media (5.41\%) and trade 


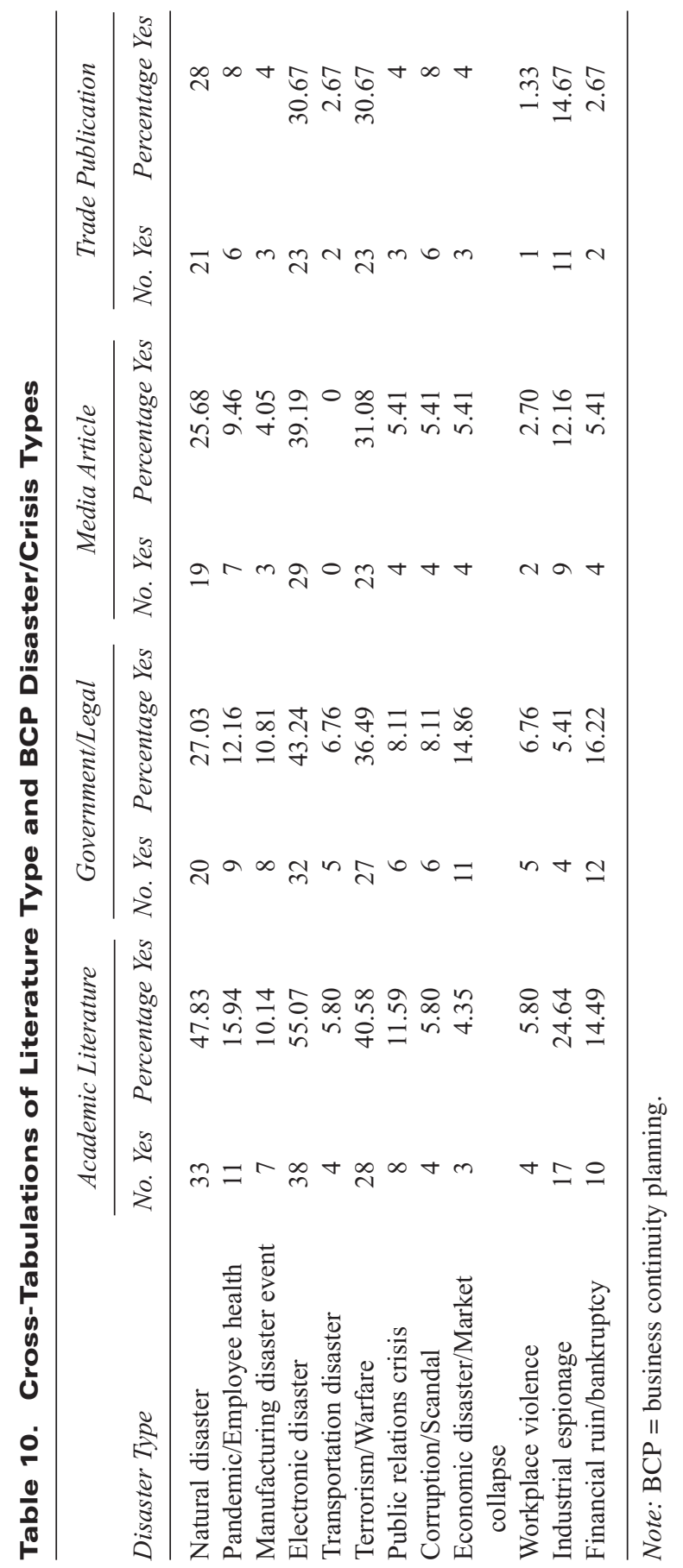




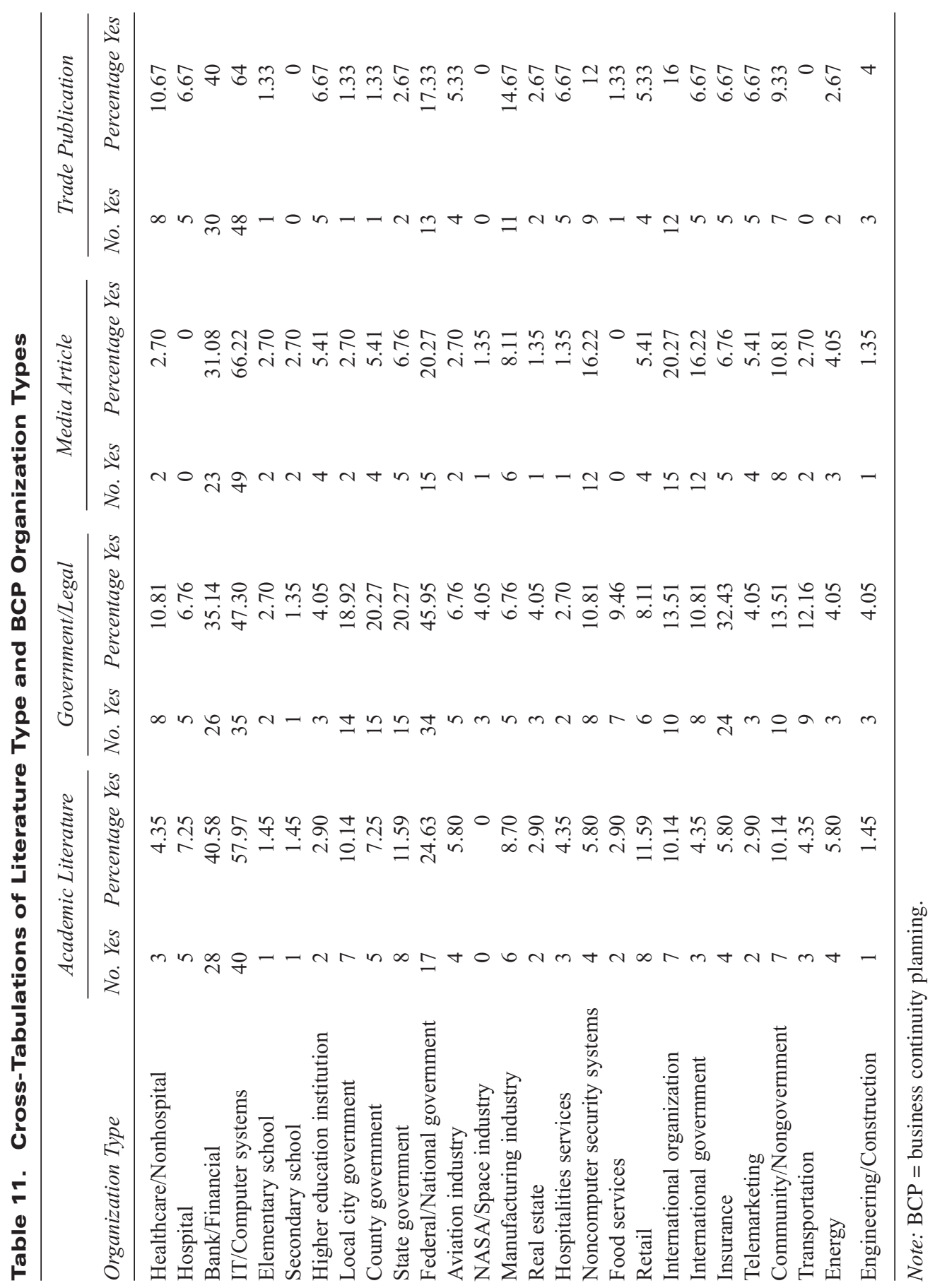




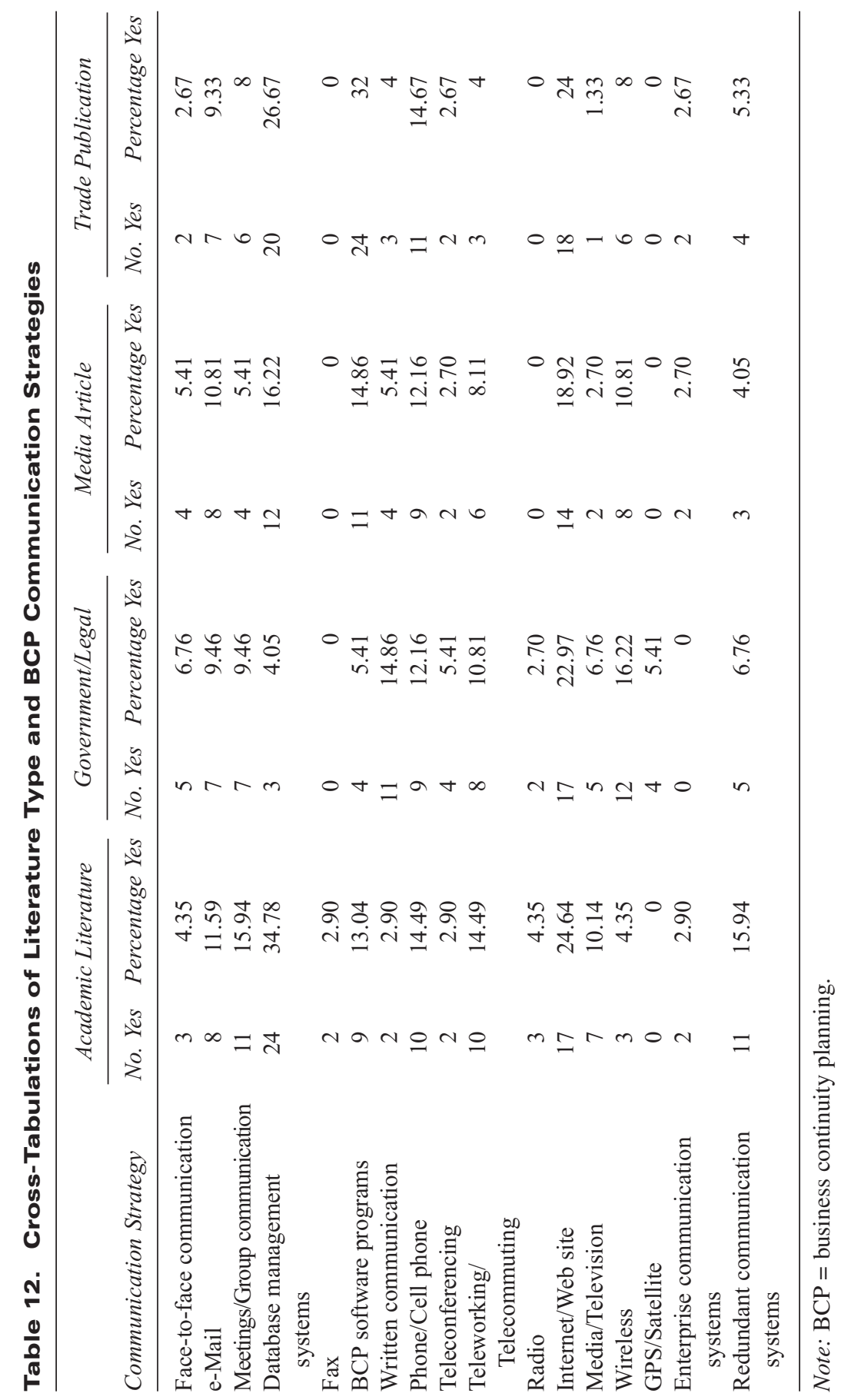




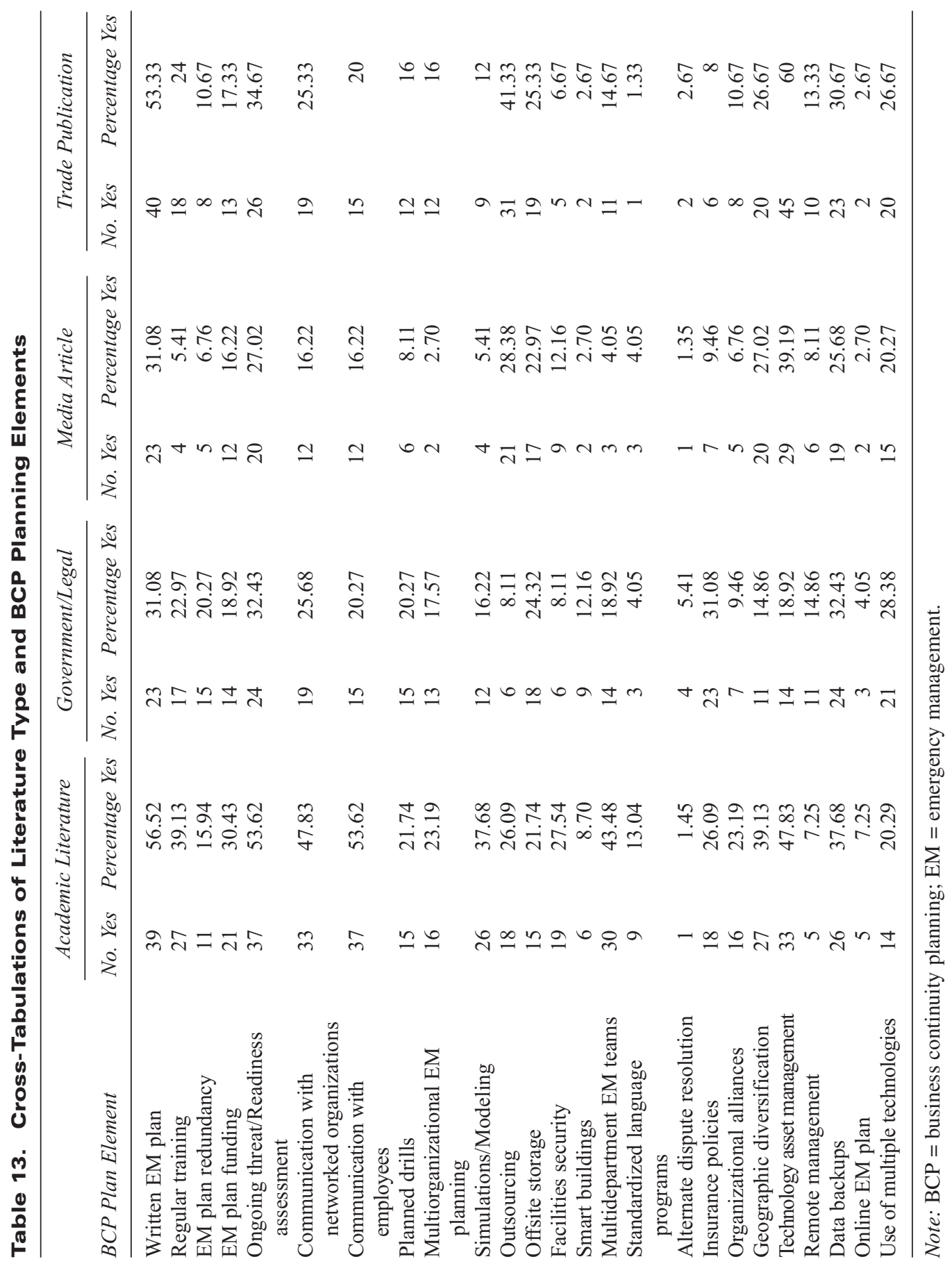




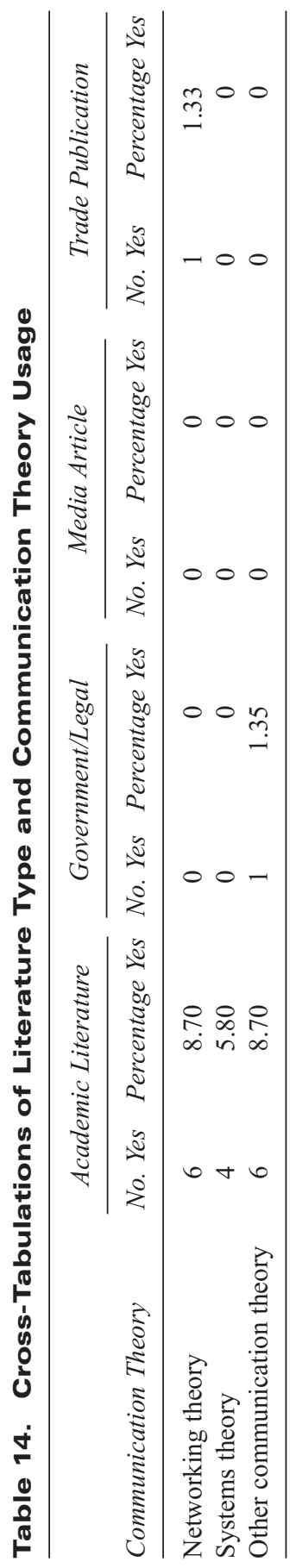


(2.67\%) publications in terms of financial disasters. These disparities seem to indicate that academics place more emphasis on a wider variety of disaster types when writing about BCP than do the other groups; whether this is due to a higher level of interest in different types of disasters than the other groups or whether this is a function of the descriptive mechanics of academic writing as compared to the other literary styles cannot be addressed in this study.

Though there were over twice as many categories for organization type (27) compared with disaster type (12) in our study, there were only two organization types that were found to be significantly represented across the bodies of literature: banking/financial $(\mathrm{A}=40.58 \%, \mathrm{G}=35.14 \%, \mathrm{M}=31.08 \%$, $\mathrm{T}=40 \%)$ and $\mathrm{IT} /$ computer systems $(\mathrm{A}=57.97 \%, \mathrm{G}=47.3 \%, \mathrm{M}=66.22 \%$, $\mathrm{T}=64 \%$ ). Table 11 provides further details of our findings concerning organization types represented in the bodies of literature. Government/legal publications were the only body of literature to demonstrate significant interest in any of the government categories (federal/national government $=45.95 \%$ ) or in the insurance industry $(32.43 \%)$.

When organization types are examined for similarity/disparity across the bodies literature, it becomes apparent that once again there are differing conversations occurring. Not surprisingly, and with the exception of local government, the government/legal publications are placing significantly higher emphasis on all levels of government BCP planning than are the others. Both the government/legal (18.92\%) and the academic (10.14\%) literature place much more emphasis on local government than do the other two groups $(\mathrm{M}=2.70 \%, \mathrm{~T}=1.33 \%)$. The government literature $(12.16 \%)$ also placed a much greater emphasis on transportation issues than did the other bodies of literature $(\mathrm{A}=4.35 \%, \mathrm{M}=2.70 \%$, and $\mathrm{T}=0 \%)$.
An analysis of the disparities between the bodies of literature in terms of disaster type demonstrates that aca- demics are having a conversation in their literature that is different from that of the other groups.

Finally, we were surprised to find that the government literature $(32.43 \%)$ is also significantly more concerned with the insurance industry than are the others $(\mathrm{A}=5.8 \%, \mathrm{M}=6.76 \%$, and $\mathrm{T}=6.67 \%)$. We found this to be a 
surprising pattern both in terms of the high level of government attention to the insurance industry and in terms of the extremely low level of attention given by the other bodies of literature, especially since proper management of insurance policies is so heavily stressed as an element of BCP planning across much of the overall BCP literature. Perhaps the interest on the part of government/legal publications is due to the need for a healthy insurance industry to act as a buffer between a disaster event and government financial support in recovery efforts (i.e., those who are insured can collect on insurance policies rather than needing to apply for government aid in the wake of a disaster), but this speculative explanation cannot be confirmed by the data collected for the purposes of this study and awaits further research.

Concerning the use of communication strategies in BCP, our analysis shows that no category of communication achieved significant representation in all of the bodies of literature (see Table 12). In fact, only the use of database management systems $(\mathrm{A}=34.78 \%, \mathrm{~T}=26.67 \%)$ was significantly represented in more than one body of literature. The only other communication strategy to achieve significant representation in any body of literature was the use of BCP software programs, which was represented in $32 \%$ of the trade publications. Finally, the most evenly dispersed communication strategy was the use of the Internet and/or Web sites $(\mathrm{A}=$ $24.64 \%, \mathrm{G}=22.97 \%, \mathrm{M}=18.92 \%, \mathrm{~T}=24 \%$ ), though it did not achieve a significant representation in any one body of literature.

In terms of disparities between the bodies of literature and communication strategies, it once again seems that there are different conversational emphases between these groups. The academic literature (34.78\%) placed significantly more emphasis on database management systems than did the other groups $(\mathrm{G}=4.05 \%, \mathrm{M}=16.22 \%, \mathrm{~T}=26.67 \%)$, and the strategy of having redundant communication systems was also more discussed by academics (15.94\%) than others $(\mathrm{G}=6.76 \%, \mathrm{M}=4.05 \%, \mathrm{~T}=5.33 \%)$. The strategy of written communication was significantly more highly represented in the government/legal literature $(14.86 \%)$ than in the other bodies of literature $(\mathrm{A}=2.9 \%, \mathrm{M}=5.41 \%, \mathrm{~T}=4 \%)$, and the government/legal literature was also the only body of literature to address the use of GPS/satellite systems (5.41\%). Finally, it is interesting to note that one other strategy was addressed by only one body of literature; academics were the only group found to be discussing the use of fax machines $(2.9 \%)$ in their body of literature on BCP.

In terms of the significant representation of BCP planning elements in the literature, three elements achieved significant representation in all four bodies: the need for written EM plans $(\mathrm{A}=56.52 \%, \mathrm{G}=31.08 \%, \mathrm{M}=31.08 \%$, $\mathrm{T}=53.33 \%)$, the need for ongoing threat/readiness assessments $(\mathrm{A}=53.62 \%$, 
$\mathrm{G}=32.43 \%, \mathrm{M}=27.02 \%, \mathrm{~T}=34.67 \%$ ), and the need for data backups $(\mathrm{A}=37.68 \%, \mathrm{G}=32.43 \%, \mathrm{M}=25.68 \%, \mathrm{~T}=30.67 \%)$. Four elements also achieved significant representation across three bodies of literature: communication with networked organizations $(\mathrm{A}=47.83 \%, \mathrm{G}=25.68 \%$, $\mathrm{T}=25.33 \%)$, the use of outsourcing $(\mathrm{A}=26.09 \%, \mathrm{M}=28.38 \%, \mathrm{~T}=41.33 \%)$, geographic diversification strategies $(A=39.13 \%, M=27.02 \%, T=26.67 \%)$, and technology asset management $(\mathrm{A}=47.83 \%, \mathrm{M}=39.19 \%, \mathrm{~T}=60 \%)$. Additionally, two elements were significantly represented in two bodies of literature: the use of insurance policies $(\mathrm{A}=26.09 \%, \mathrm{G}=31.08 \%)$ and the use of multiple technologies $(\mathrm{G}=28.38 \%, \mathrm{~T}=26.67 \%)$. Finally, significant representation was achieved in one body of literature by seven elements: regular training $(\mathrm{A}=39.13 \%)$, EM plan funding $(\mathrm{A}=30.43 \%)$, communication with employees $(\mathrm{A}=53.62 \%)$, the use of simulations/modeling $(\mathrm{A}=37.68 \%)$, offsite storage $(\mathrm{T}=25.33 \%)$, facilities security $(\mathrm{A}=27.54 \%)$, and the use of multidepartment EM teams $(\mathrm{A}=43.48 \%)$.

Analysis of the disparities between the bodies of literature and the $\mathrm{BCP}$ planning elements demonstrates the clearest evidence supporting our argument that different conversations are occurring between these groups. As can be seen in Table 13, the use of written EM plans has significantly more representation in the literature of academics $(56.52 \%)$ and the trades $(53.33 \%)$ than those of the other groups $(\mathrm{G}=31.08 \%, \mathrm{M}=31.08 \%)$, and the use of insurance policies is more frequently discussed in the literature of academics (26.09\%) and government/legal sources (31.08\%) than those of the other two groups $(\mathrm{M}=9.46 \%, \mathrm{~T}=8 \%)$. The trade publications address outsourcing $(41.33 \%)$ significantly more often than the other groups of literature $(\mathrm{A}=$ $26.09 \%, \mathrm{G}=8.11 \%, \mathrm{M}=28.38 \%$ ). The issue of technology asset management is also more highly represented in the trade publications $(60 \%)$ than in other literature ( $\mathrm{A}=47.83 \%, \mathrm{G}=18.92 \%, \mathrm{M}=39.19 \%)$.

Finally, there are multiple strategy elements that the academic literature discusses significantly more often than any of the other bodies of literature. These elements include the use of regular training $(\mathrm{A}=39.13 \%, \mathrm{G}=22.97 \%$, $\mathrm{M}=5.41 \%, \mathrm{~T}=24 \%), \mathrm{EM}$ plan funding $(\mathrm{A}=30.43 \%, \mathrm{G}=18.92 \%$, $\mathrm{M}=16.22 \%, \mathrm{~T}=17.33 \%)$, threat/readiness assessment $(\mathrm{A}=53.62 \%, \mathrm{G}=$ $32.43 \%, \mathrm{M}=27.02 \%, \mathrm{~T}=34.67 \%$ ), communication with networked organizations $(\mathrm{A}=47.83 \%, \mathrm{G}=25.68 \%, \mathrm{M}=16.22 \%, \mathrm{~T}=25.33 \%)$, communication with employees $(\mathrm{A}=53.62 \%, \mathrm{G}=20.27 \%, \mathrm{M}=16.22 \%, \mathrm{~T}=25.33 \%)$, simulations/modeling $(\mathrm{A}=37.68 \%, \mathrm{G}=16.22 \%, \mathrm{M}=5.41 \%, \mathrm{~T}=12 \%)$, facilities security $(A=27.54 \%, G=8.11 \%, M=12.16 \%, T=6.67 \%)$, the use of multidepartment EM teams $(A=43.48 \%, G=18.92 \%, M=4.05 \%$, $\mathrm{T}=14.67 \%)$, standardized language programs $(\mathrm{A}=13.04 \%, \mathrm{G}=4.05 \%$, 
$\mathrm{M}=4.05 \%, \mathrm{~T}=1.33 \%$ ), the use of organizational alliances $(\mathrm{A}=23.19 \%$, $\mathrm{G}=9.46 \%, \mathrm{M}=6.76 \%, \mathrm{~T}=10.67 \%)$, and geographic diversification strategies $(\mathrm{A}=39.13 \%, \mathrm{G}=14.86 \%, \mathrm{M}=27.02 \%, \mathrm{~T}=26.67 \%)$. These vast disparities between the various bodies of literature and their representation of the various BCP strategy elements seems to indicate that the different groups who are producing these studies have differing levels of focus on the issues related to $\mathrm{BCP}$ and that, to some extent, each of these groups' conversations in the literature are focused on different $\mathrm{BCP}$ elements.

Finally, we can see how little any of these bodies of literature include communication theories in their discussion of BCP. None of the communication theories (including the "other" catch-all category) even came close to achieving significant representation in any of the bodies of literature. We found that practitioners in the media literature present almost no communication theories in their work. Both networking theory and other communication theories were discussed in the nonacademic literature, though this representation was very weak (one article in the trade publications mentioned networking theory, and one article in the government/legal literature mentioned another communication theory). Perhaps what is most disturbing from the perspective of the application of communication scholarship in the wider discourse is that even the academic literature demonstrated a weak showing for discussing communication theory: Only $23 \%$ of the academic literature made any mention of any communication theory. Our findings concerning the presence of communication theories in the bodies of literature explored in this study are summarized in Table 14.

\section{Discussion}

\section{Limitations}

This project was exploratory in nature. We wanted to find out what kinds of literature, if any, appeared regarding BCP and strategic communication within and among organizations. We narrowed our choices to journal type articles from academia, trade, and government/legal and media news stories because we felt that that was where we would find the bulk of the information for practitioners as well as any theoretical arguments from scholars. We did not include several pertinent subareas from databases such as the NASA articles from Web of Science, which contained almost 40,000 hits. In addition, in LexisNexis, we did not cover major business and international subsets that might be relevant. Moreover, we did not review books or any mass media 
outlets, including television, the radio, or the Internet. There is definitely room for more research in all of these areas.

A second restriction was the categories used in the study. We can define the variables more clearly by using specific subsets of how the literature classifies different crisis events. For example, in the energy sector, there are several specific types of accidents, from a nuclear meltdown to blackouts to environmental issues. Each variable was intentionally broad in scope due to the study being exploratory in nature. We can go into each specific category to find additional information. Once we have enough data, we can potentially make predictions across various organizational groups to see how they can increase their collaboration in BCP. More importantly, the collection of additional data on $\mathrm{BCP}$ will continue the process of knowledge management in $\mathrm{BCP}$, thereby leading toward a better understanding of the gaps in knowledge that need to be addressed by both practitioners and researchers.

\section{Future Research Directions}

We confirmed our initial suspicions about the lip service given to $\mathrm{BCP}$ as a priority for organizations (except in the case of some IT departments, the banking and finance industry, and the considerable work done by the varying domestic federal and local governments, where it appears that actual implementation of $\mathrm{BCP}$ principles is being carried out to some extent). It appears that most of the literature we examined uses BCP as a buzzword or for rhetorical appeal, but there is minimal detail on what $\mathrm{BCP}$ actually is (especially in relation to strategic communication) and how to make it more effective. Furthermore, we know that three additional complications (costs, time, and legal battles) make it difficult for some organizations who want to implement $\mathrm{BCP}$ to proceed.

We also found that certain technologies are preferable when organizations do communicate their BCP strategies. However, the specific details on how they function and if they are successful are missing (both in the literature and in this study). It seems to us that understanding these technologies should be a key element of managing BCP knowledge because knowing how, if, and why a technology works in BCP is essential to making informed decisions about what technologies to implement in an organization.

There also needs to be a broadening of the scope concerning which types of organizations should implement BCP strategies. The primary focus of he literary work we found was on industry and government, but $\mathrm{BCP}$ is potentially applicable across a much wider array of organizations within 
society. Crises are not just national events; local individuals and groups who experience them also need to implement and adapt management and recovery strategies. Finally, some organizations and groups might not even consider BCP as a necessity either because of unawareness of BCP concepts, unrealistic optimism about their ability to recover, or a tendency to minimize or deny the risks that they face. We can do more research to overcome these misguided assumptions and help organizations and communities attain a certain amount of protection from potential disasters.

Furthermore, there is limited information on the cultural aspects of BCP. The way in which cultures communicate and deal with crises may differ vastly. Perhaps, accounting for diverse cultural perspectives could help a broader range of cultures to do a better job of communicating their crisis and disaster preparation needs before and during a disaster event. We do not understand why the BCP literature ignores entire continents, including Asia, South America, parts of Africa, and the Middle East. Considering the globalized nature of the economy, there should be at least a profit motive to encourage the sharing of BCP information and techniques across the existing boundaries between cultures, nations, fields of knowledge, and industries.

In addition, considering how much attention the government paid to insurance companies, banks, and IT plans in the financial sector, it would seem reasonable that they should have been prepared for this coming recession and could have planned better accordingly. It would be interesting to include in a future study the impacts of the lack of BCP, which could have quickly dealt with this economic crisis rather than seeing it drag on for more than a year.

Finally, we are concerned with how little communication theory is represented in the literature. Perhaps, it is because theory is often too abstract that practitioners find it of little use or value when trying to plan for future crises. Future research should consider how organizations could make theory more useful in the planning process, so rather than being reactive to events when damage is done and profits have been lost, we can take a more proactive stance.

In conclusion, O'Hair (2007) articulates that (where possible) communication scholars have a responsibility to help solve humanity's problems. He explains that the best research and theory in our field is also practical. It is important that the work that we do is useful and applicable to organizational realities. We see this study as a small step in the direction of pushing the boundaries of our field beyond the academy and into the realm of applied knowledge. 


\section{APPENDIX}

Item 1: Initial BCP Article Code Sheet

\section{Basic Text Information}

\section{Title:}

Author(s):

Source:

Type of Text:

Date of Publication:

Study Unit \#:

\section{Type of Event BCP Utilized For}

_ Natural Disaster

- Pandemic/ Employee Health

_ Manufacturing Disaster Event

$$
\begin{aligned}
& \text { Transportation Disaster } \\
& \text { — Terrorism/Warfare } \\
& \text { _ Public Relations Crisis }
\end{aligned}
$$

\section{Organization Types Represented in Unit}

_ Healthcare/Nonhospital

_ Hospital

- Bank/Financial

_ IT/Computer Systems

- Elementary School

— Secondary School
_ Higher education Local/City government

_ County government

_ State government

Federal government

_ Aviation
NASA/Space programs

_ Manufacturing

- Hospitalities services

— Security systems

_ (Noncomputer)

\section{Types of Communication Technology Utilized:}

Ftf Communication

E-mail Communication

_ Meetings/Group Communication

_ Database Management Systems

_ BCP Software Programs
Written Communication

- Phone Communication

— Teleconferencing

_ Radio Communication

Name of System(s):

\section{BCP Strategy Elements:}

_ Written EM Plan

_ Regular Training

_ EM Plan Redundancy

_ Funding for EM Readiness

— Ongoing Threat/Readiness Assessment
Regular Communication with Networked Orgs. Communicate with Employees

Planned Drills Multi-Organizational EM Planning Computer Simulations 


\section{APPENDIX (continued)}

Theoretical Frameworks for Communication Strategy:

Networking Theory

_ Systems Theory

Item 2: Final BCP Article Code Sheet

Coder Number:

\section{Basic Text Information:}

Title of Article:

Author(s):

Journal/ Source:

Type of Text:

Date of Publication:

Study Unit \#:
Academic Media Government/Legal Trade

Type of Event BCP Utilized for:

Natural Disaster

Pandemic/Employee Health

Manufacturing Disaster

— Electronic Disaster
_ Transportation Disaster

_ Terrorism/Warfare

Public Relations Crisis

Corruption/Scandal
Economic Disaster/

Market Collapse

_ Workplace Violence

Industrial Espionage

Financial Ruin/

Bankruptcy

Organization Type Represented in Unit:

Healthcare/Non-hospital

_ Hospital

- Bank/Financial

_ IT/Computer Systems

Elementary School

— Secondary School

_ Higher Education Institution

_ Local City Government

— County Government

_ Federal/National Government

- County Government

_ Federal/National Government
Manufacturing Industry

_ Real Estate

_ Hospitalities Services

_ Non-computer Security Systems

_ Food Services

_ Retail Industry

_ International Organization

International Government

_ Insurance Industry

_ Telemarketing/Call Center

_ Community/Non-government

_ Transportation Industry 


\section{APPENDIX (continued)}

Aviation Industry

_ NASA/Space Industry
Energy Industry

_ Engineering/Construction

Types of Communication Technology Utilized:

FtF Communication

E-mail

_ Meetings/Group Communication

_ Database Management Systems

- Fax

_ BCP Software (list type(s)

on back of code sheet)

Written Communication

_ Phone/Cell Phone

— Teleconferencing

\section{BCP Strategy Elements:}

_ Written EM Plan

_ Regular Training

EM Plan Redundancy

_ EM Plan Funding

_ Ongoing Threat/Readiness Assessment

_ Communication with Networked Organizations

Communication with Employees Planned Drills

_ Multi-organization EM Planning

_ Simulations/Modeling

_ Outsourcing

— Offsite Storage

— Facilities Security
_ Teleworking/Telecommuting

- Radio

- Internet/Website

- Media/T.V.

— Wireless Technology

_ GPS/Satellite Systems

Enterprise Communications Systems

_ Redundant Communications Systems

\section{Theoretical Frameworks for Communication Strategy:}

Networking Theory

_ Systems Theory

_ Other(s) (please list):

\section{NOTES}

1. This refers to books, reports, data files, or any physically available information.

2. Implicit knowledge artifacts refer to interpreting and inferring information based on prior context and understanding. 
3. Tacit knowledge artifacts include personally known information through experience with the organization. This could include anything from office culture and rumors to the internal workings of a budget or the way things get done.

\section{REFERENCES}

9/11 Commission. (2004). 9/11 Commission Report: Final Report of the National Commission on Terrorist Attacks Upon the United States. New York: Barnes \& Noble.

Aucote, H. M., \& Gold, R. S. (2005). Non-equivalence of direct and indirect measures of unrealistic optimism. Psychology, Health \& Medicine, 10, 376-383.

Bajgoric, N. (2006). Information systems for e-business continuance: A systems approach. Kybernetes, 35, 632-652.

Botha, R. A., \& Gaadingwe, T. G. (2006). Reflecting on 20 SEC conferences. Computers \& Security, 25, 247-256.

Carter, R. L., Jr. (1998). Bracing for the millennium bug: Consider liability coverage to protect businesses facing Y2K claims. American Bar Association Journal, 84, 64.

Cohen, J. (1960). A coefficient of agreement for nominal scales. Educational and Psychological Measurement, 20, 37-46.

Covey, J. A., \& Davies, A. D. M. (2004). Are people unrealistically optimistic? It depends how you ask them. British Journal of Health Psychology, 9, 39-49.

Edmonson, R. G. (2006, November 2). Security a tough sell to top managers: Survey [Electronic version]. Retrieved from http://proquest.umi.com.ezproxy.lib.ou.edu/ pqdweb? did=1155939411\&sid=2\&Fmt=3\&clientId=41954\&RQT=309\&VName=PQD

Gill, T. J. (2006). Workplace continuity: How risk and technology will affect facilities strategy. Journal of Facilities Management, 4, 110-125.

Hanna, G. (2005). How to take a computer disaster in stride. Strategic Finance, 86, 48-52.

Hermand, D., Karsenty, S., Py, Y., Guillet, L., Chauvin, B., Simeone, A., et al. (2003). Rejection of crisis information: Public apathy and the macro-crisis of Y2K. Society for Risk Analysis, 23, 821-828.

Hofstede, G., Van Deusen, C. A., Mueller, C. B., Charles, T. A., \& The Business Goals Network. (2002). What goals do business leaders pursue? Journal of International Business Studies, 33, 785-803.

Iyer, R. K., \& Bandyopadhyay, K. (2000). Managing technology risks in the healthcare sector: Disaster recovery and business continuity planning. Disaster Prevention \& Management, 9, 257-270.

Jackson, R. (2006). Business continuity: Preparation over prevention. Accountancy Ireland, 38, 51-53.

Kelly, S., \& Peckham, R. (2002). Prepared for the worst. Communication News, 39, 12-18.

Maher, K., \& Zimmerman, A. (2005, September 6). In Katrina's wake: Gulf firms seek to assist workers, resume business. The Wall Street Journal, p. A-10.

MCC. (2005). Standards for survival. Metropolitan Corporate Counsel Inc. Kirpatrick \& Lock Section, 13.

National Fire Protection Association. (2007). NFPA 1600 standard on disaster/emergency management and business continuity programs. Quincy, MA: Author.

Newman, B., Conrad, K.K. (1999), "A framework for charactering knowledge management methods, practices, and technologies", paper presented at Choosing Knowledge Management Technology Panel, at Santa Clara, CA, February. 
Norris, F. (2008, November 1). A monthlong walk on the wildest side of the stock market. The New York Times, Section B 1.

O'Hair, D. (2007). The promise of communication: A presidential address. National Communication Association, Spectra, 43(2), 6-10.

Park, E., Scherer, C. W., \& Glynn, C. J. (2001). Community involvement and risk perception at personal and societal levels. Health, Risk, \& Society, 3, 281-292.

Pearl, M. A. (1998). Responding to the year 2000 challenge: Building partnerships towards a solution not litigation. Metropolitan Corporate Counsel Inc. In House Perspectives Section, 23.

Perry, R. W., \& Mankin, L. D. (2005). Preparing for the unthinkable: Managers, terrorism and the HRM function. Public Personnel Management, 34, 175-193.

Pitt, M., \& Goyal, S. (2004). Business continuity planning as a facilities management tool. Facilities, 22, 87-99.

Powell, L., Bodon, J., \& Hickson, M., III. (2001). Rejection of crisis information: Public apathy and the macro-crisis of Y2K. Communication Research Reports, 18, 84-92.

Ramleth, G. (2006). Q\&A: Global issues. Optimize, 5, 38.

Swartz, N. (2003). Few organizations have effective continuity plans. Information Management Journal, 37, 7.

Then, K. S., \& Loosemore, M. (2006). Terrorism prevention, preparedness, and response in built facilities. Facilities, 24, 157-176.

Willemssen, J. C. (1998). Year 2000 computing crisis: Significance risk remains to Department of Education's student financial aid systems. Testimony before the subcommittee on oversight \& investigations, committee on education and the workforce (House of Representatives GAO/T-AIMD-98-302-September, 17, 1998). Washington, DC: U.S. Government Printing Office. 